\section{ESPACIO Y METALURGIA EN LA CULTURA CASTREÑA: LA ZONA ARQUEOLOGICA DE LAS MEDULAS}

\author{
SPACE AND METALLURGY IN THE \\ "CULTURA CASTREÑA": \\ THE ARCHAEOLOGICAL REGION \\ OF LAS MEDULAS
}

\author{
M. $^{a}$ DOLORES FERNANDEZ-POSSE $(*)$ \\ IGNACIO MONTERO (*) \\ F. JAVIER SANCHEZ-PALENCIA (**) \\ SALVADOR ROVIRA $(* * *)$
}

\section{RESUMEN}

A partir del análisis espacial de la producción metalúrgica de dos castros prerromanos astures se establece la existencia de un artesano metalúrgico a tiempo completo, que actúa como suministrador de todo el poblado desde una unidad de ocupación. Se determina su posición social y su desarrollo tecnológico, así como el ámbito de su producción. También se discuten las posibilidades de abastecimiento de materias primas y los fenómenos interactivos dentro del ámbito de la Cultura Castreña del NW.

A modo de contraste, se analiza el cambio que experimenta la producción metalúrgica en dos yacimientos cercanos de época romana cuando la zona ha entrado ya dentro de un nuevo sistema de ocupación, a raíz de la explotación intensiva de sus recursos auriferos.

\section{RESUMÉE}

L'anayse spatiale de production métallurgique de deux castros préromains astures nous permet de déterminer la présence d'un artisanat métallurgique à plein temps, qui agit comme le fournisseur de la communauté dès une "unité

(*) Departamento de Arqueología ICRBC del Ministerio de Cultura.

(**) Departamento de Arqueología, CEH del CSIC.

$(* * *)$ Museo de América. d'occupation". Il est égalment possible de determiner sa position sociale et le niveau de developpement technologique, ainsi que le cadre de sa production. Les possibilités d'approvisionnement de matière première et les phenomènes interactifs dans le cadre de la Cultura Castreña du Nord-Ouest de la Péninsule Ibérique sont ensuite discutées.

Comme point de repère nous analysons le changement que subit la production métallurgique dans deux sites archéologiques proches mais appartenant à l'époque romaine, lorsque la zone est déjà integrée dans un nouveau système d'occupation, motivé par l'exploitation de l'or.

\footnotetext{
ABSTRACT

Spatial analysis of metallurgical production at two preRoman castros of the Astures indicates that a full-time metallurgical especialist supplied each village from a single area of occupation. It is possible to determine the craftsman's social position, his level of technological expertise, as well as the scope of his production. We also discuss the supply of raw material and the commerce within the region of the "Cultura Castreña" of northwest Iberia. By way of contrast, we analyze metallurgical production at two nearby Roman sites that belong to a period when intensive gold production had changed patterns of production and exploitation.
} 
Palabras clave: Metalurgia. Prerromana. Astur. Social. Modos de producción.

Key words: Metallurgy. Pre-roman. «Astur». Social. Modes of production.

Dentro de un proyecto a escala regional que estamos llevando a cabo en el Suroeste de León (Fig. 1) y cuya finalidad última es el conocimiento de las transformaciones sociales producidas en las poblaciones indígenas por el contacto romano, hemos tenido ocasión de caracterizar a las comunidades prerromanas astures que ocuparon la zona en los dos siglos anteriores al cambio de Era. El hecho de que uno de los aspectos más interesantes de lo que hasta el momento hemos documentado sobre ellas lo constituya su metalurgia, nos lleva a plantear este trabajo.

Los astures prerromanos son poblaciones castreñas, es decir, su tipo de asentamiento es el castro. Estos castros se situan en emplazamientos muy selectivos de topografía muy regular y constituyen recintos bien delimitados natural y artificialmente. Son de tamaño reducido - nunca sobrepasan las $2 \mathrm{Ha}$ - y albergaban a comunidades también reducidas. Sin embargo, son la unidad básica de ocupación del territorio hasta sus últimas consecuencias sociales. Es decir, cada castro es una comunidad social independiente que desarrolla de forma autárquica una economía de subsistencia de base agropecuaria. Esta falta de cohesión entre los diversos castros tiene su reverso en la organización del espacio interior de cada uno de ellos. En efecto, existe una fuerte interdependencia social y económica entre las unidades de ocupación que componen el asentamiento, cuyo carácter cerrado queda aún más de manifiesto en la importancia de los elementos constructivos que lo delimitan - ya sean parapetos, murallas o fosos-, dotados así de un significado sociocultural que transciende lo meramente defensivo.

Por otro lado, son comunidades que se mantienen en un relativo aislamiento de otros grupos culturales cercanos. Así se explica, por ejemplo, que sólo con la presencia romana se introduzca en la zona el molino circular o la cerámica a torno de tipo celtibérico. Sin embargo, este menor desarrollo técnico permite establecer un basculamiento de la zona hacia el círculo de la Cultura Castreña gallega, sin necesidad de preconizar arcaismos atribuidos, en ocasiones abusivamente, a zonas retiradas.

En dos de esos castros prerromanos leoneses, $\tan$ sucintamente definidos, hemos realizado excavaciones. El primero de ellos es La Corona de Corporales (1). Está situado en la cima de una colina sobre el curso alto del río Eria, al pie de la vertiente sur de la Sierra del Teleno, en la comarca leonesa de la Cabrera Alta; muy cerca por tanto de la divisoria entre las cuencas del Duero y del Sil y de uno de los pasos de comunicación entre la Meseta y Galicia. El segundo es El Castrelín de San Juan de Paluezas (2), sobre la margen izquierda del río Sil. Se emplaza en un espolón definido por dos encajados arroyos desde el que se domina casi todo El Bierzo. Su lado sur, el único relativamente accesible, se prolonga en un paisaje alomado hasta el paso natural de estas tierras sobre el Sil a la Subfosa de Las Médulas.

En ambos castros ha sido puesta al descubierto la suficiente extensión de su núcleo edificado para entender cómo su espacio interno se organiza por medio de las más arriba citadas unidades de ocupación. Estas unidades pueden quedar definidas como la estructura mínima desde el punto de vista espacial, económico y social de esa comunidad que es el castro. Es decir, es el instrumento por medio del cual se desarrolla el espacio construido, la unidad básica de producción y el núcleo social menor. Están compuestas por un conjunto de construcciones

(1) Las memorias de las excavaciones realizadas en este asentamiento castreño han sido publicadas ya, así como algunos trabajos de analítica espacial sobre el propio yacimiento y sobre el territorio en que se integra: F.-J. Sánchez-Palencia y M. D. Fernández-Posse, 1985; F.-J. Sánchez-Palencia y M. D. Fernández-Posse, 1986; M. D. Fernández-Posse y F.-J. Sánchez-Palencia, 1988.

(2) En este yacimiento se han realizado dos cortas campañas de excavación en 1990 y en 1991. Esos trabajos se integran en el Proyecto de investigación "Zona Arqueológica de Las Médulas" que se realiza en el Centro de Estudios Históricos del CSIC y está subvencionado por la Junta de Castilla y León. Una noticia preliminar sobre el Proyecto puede verse en: F.-J. Sánchez-Palencia, M. D. FernándezPosse, J. Fernández Manzano, Y. Alvarez y L. F. López, 1990. 


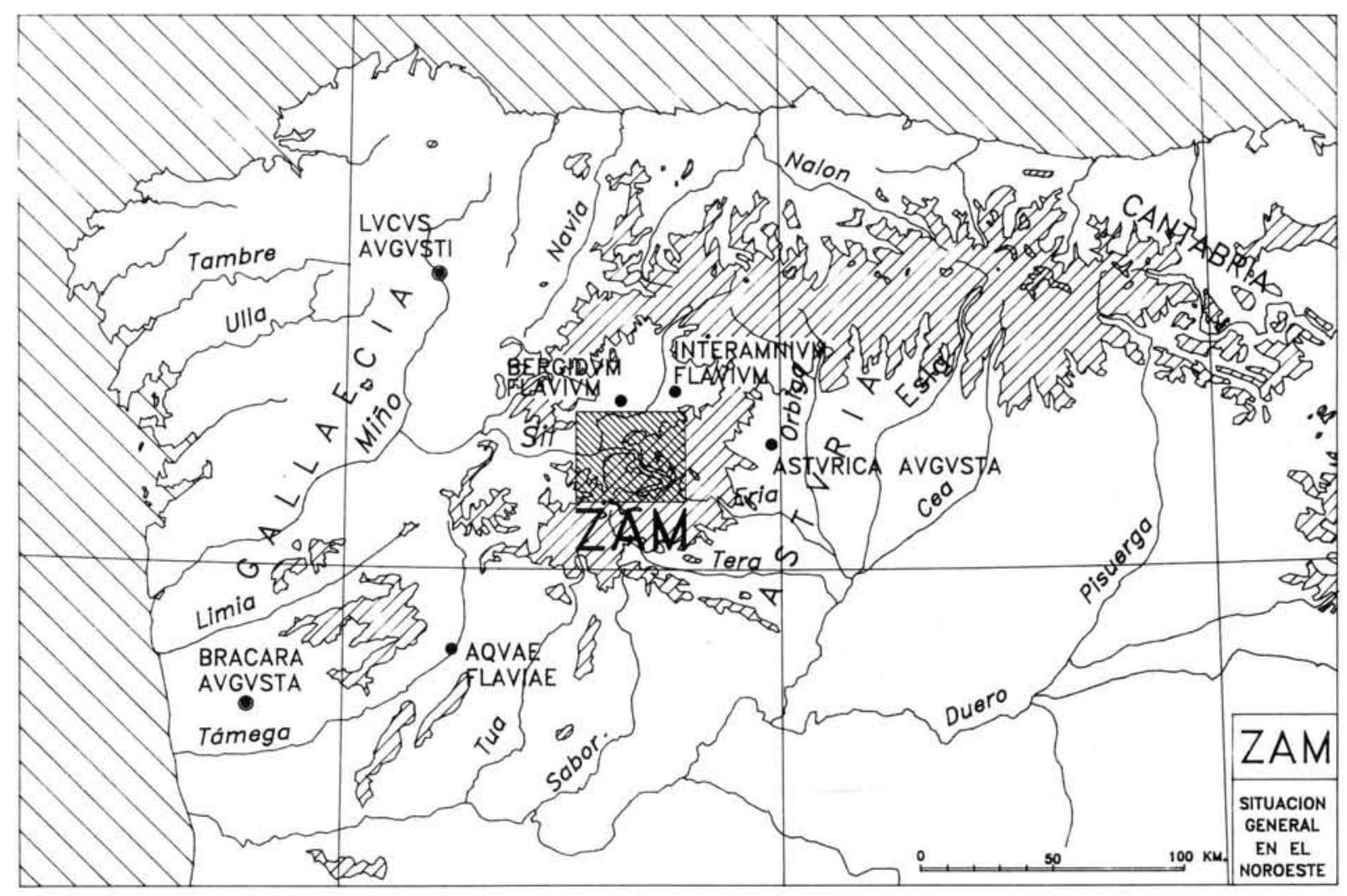

Fig. 1. Situación de la Zona Arqueológica de Las Médulas en el Noroeste peninsular.

de diferente funcionalidad y características que van desde los espacios estrictamente domésticos de cocina y vivienda hasta los anejos de trabajo, los almacenes o los espacios abiertos más o menos acondicionados. Estos conjuntos, cuya independencia espacial es siempre muy marcada, tienen una composición muy diferente, tanto por el número de construcciones que los forman como por la cantidad de espacio útil o disponible. Como vemos en la figura 2, en La Corona de Corporales excavamos al menos 6 unidades de ocupación, mientras que en El Castrelín de San Juan de Paluezas, en donde aún no se han finalizado los trabajos de campo, contamos ya con 4 (Fig. 3).

Algo que también ha quedado claro en el curso de esas excavaciones son las diversas tendencias en la actividad económica que presentan las unidades de ocupación, diferenciación funcional que es, además, complementaria dentro del poblado. En el caso de La Corona el poder establecer esas conclusiones ha sido favo- recido por las especiales circunstancias de su destrucción y abandono: se trata de un castro destruido violentamente de forma que ha quedado fijado, bajo los derrumbes provocados de las techumbres y paredes, el nivel de ocupación en su último momento de uso. Hemos situado la destrucción de este asentamiento en el curso de los enfrentamientos de romanos e indígenas durante los episodios que culminaron con la integración del Noroeste en el mundo romano. Un proceso de destrucción muy diferente presenta El Castrelín, ya que su abandono se produjo en unas condiciones de tranquilidad que permitió a sus habitantes llevar consigo la mayor parte de los enseres en uso o efectuar sobre ellos una exhaustiva selección. Nuestra hipótesis en este caso es que se trata de un castro desalojado. De esta forma mientras que en La Corona el análisis del tipo y distribución de los hallazgos permite fijar con cierta garantías la funcionalidad de los espacios, en El Castrelín —en el que además se suma la dificultad de ser 


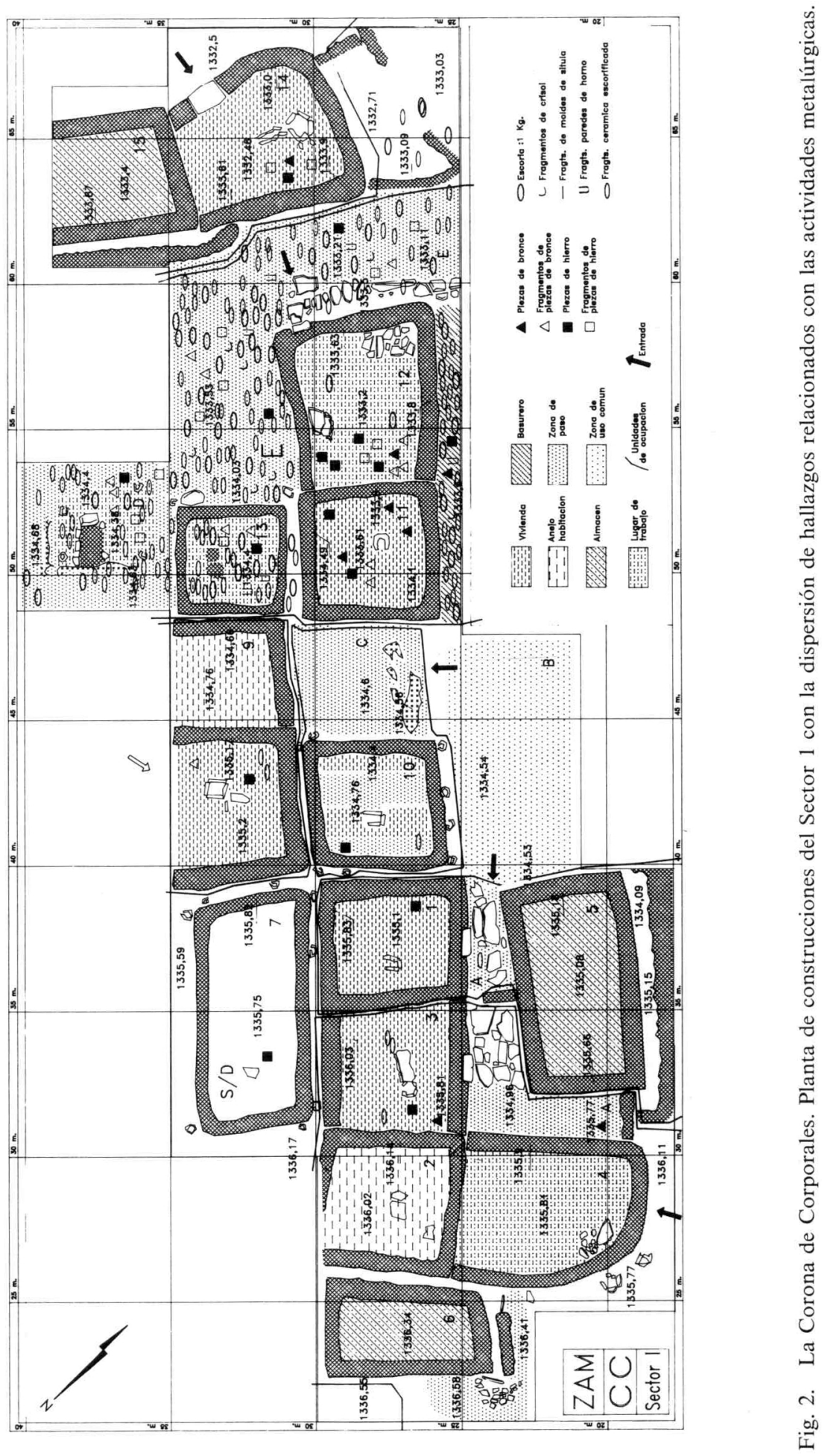

T. P., $\mathrm{n}^{\circ} 50,1993$ 


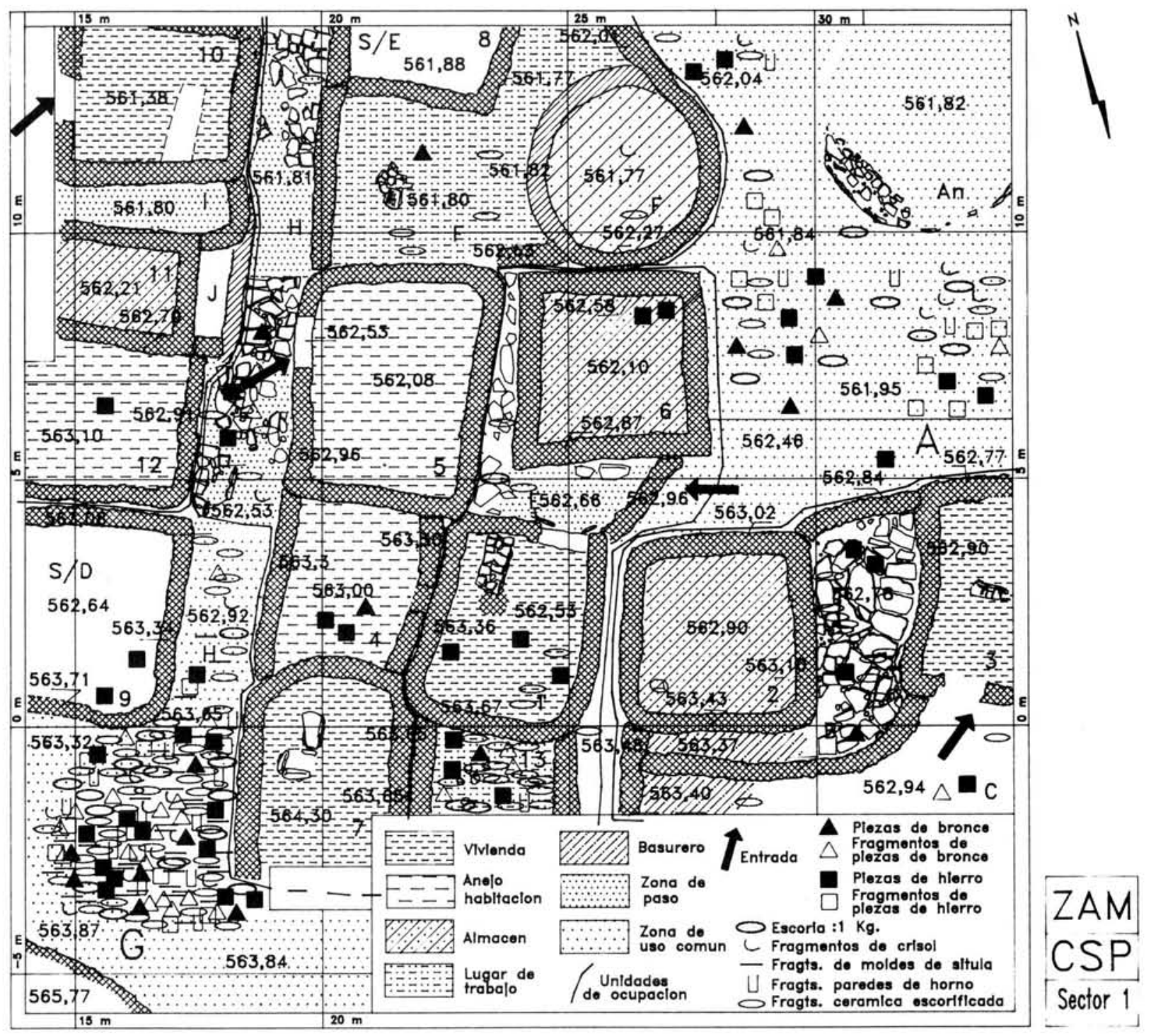

Fig. 3. El Castrelín de San Juan de Paluezas. Planta de las construcciones del Sector I con la dispersión de hallazgos relacionados con las actividades metalúrgicas.

un poblado de más larga y más intensa vida constructiva- esto resulta a veces más complicado. De todas formas, utilizando el modelo de ordenación espacial tan netamente definido en La Corona y los datos que proporcionan algunos de los espacios residuales de El Castrelín, como son los de vertido, hemos podido subsanar algunas carencias derivadas de su abandono y su lenta destrucción posterior.

\section{LA METALURGIA COMO ACTIVIDAD ESPECIALIZADA EN LOS CASTROS PRERROMANOS}

En La Corona de Corporales una de sus unidades de ocupación refleja de forma expresiva, en sus características y materiales, la actividad económica desarrollada por sus ocupantes. Se trata de una vivienda, la construcción 11 de 
la figura 2, sus talleres y espacios anejos en los que existía una dedicación prioritaria a las labores metalúrgicas. Esta unidad de ocupación está compuesta por tres construcciones, un espacio semicubierto y todo un entorno de espacios abiertos y libres sobre los que claramente ejercía un uso continuo y exclusivo. No vamos a repetir los datos que se refieren a su excavación, para los que remitimos a los trabajos antes citados, pero sí queremos recordar brevemente algunas de sus características constructivas.

La vivienda 11, cuya funcionalidad atestiguan hogar, mobiliario y ajuar, fue levantada exenta. A su lado sureste se adosó otra habitación, la 12, de mayor tamaño y forma muy aproximadamente rectangular, en cuya fachada suroriental se abría el umbral. Esta especie de gran vestíbulo se utilizó como anejo/taller y estaba dotado de una instalación, donde eventualmente se hacía fuego, y de un pequeño espacio enlosado. Sus materiales, entre los que abundan los metálicos y la escoria, confirman su funcionalidad. Ambas construcciones tuvieron una cubierta unitaria, presumiblemente a dos aguas, sobre muros alzados totalmente en piedra. Al noroeste de la habitacion-vivienda y separada de ella por un estrecho caleyo que no supera el medio metro de anchura, se encuentra la tercera de las construcciones. Es una pequeña habitación de forma cuadrada y muros estrechos e irregulares. Esas y otras dëficiencias de su estructura hicieron necesarios, pese a su reducido tamaño, algunos pies derechos para el apoyo de su cubierta. Probablemente su alzada no fuera totalmente de piedra e, incluso, cabe pensar que se tratase solamente de un alto zócalo. Es decir, estamos ante un cobertizo donde se realizaban unas funciones muy específicas. Así lo indican la presencia en su pavimento de dos hoyos de fundición, la acumulación de madera - que se utilizaría como combustible-y los materiales encontrados en su interior. Este taller anejo a las dos construcciones se completa con una instalación situada en su lado nororiental y bien delimitada por cuatro postes que debieron sujetar una cubierta ligera. Bajo este techado, tallado en la roca y con algunas piedras de calzo, existe un tercer hoyo de fundición y una gruesa piedra . plana. Tanto en el cobertizo como en este último espacio semicubierto que hemos llamado $\mathrm{D}$, la escoria era abundante.
Todo el espacio abierto al noreste de la construcción 12 hasta los muros de la 14 y 15 , de un lado, y la "calle" que se forma al sureste entre las mismas construcciones, de otro, fueron ambientes utilizados por la unidad de ocupación que examinamos (Fig. 2). Que así fue, lo indica la notable cantidad de escoria, la cerámica desechada reutilizada en labores de fundición y otros hallazgos más específicos, como los fragmentos de crisol, que de allí proceden. De igual forma, otros espacios libres situados al sureste de esta unidad de ocupación metalúrgica fueron utilizados como zona de vertido por sus ocupantes.

Todas estas construcciones que hemos descrito brevemente, revelan en su disposición espacial y en los materiales asociados una integración unitaria nada común que marca netamente su independencia de las demás construcciones, por más que éstas las rodeen casi totalmente y de forma apretada. Esta independencia queda de manifiesto en circunstancias tan expresivas como el que el frágil y reducido cobertizo 13 no se apoye, como sería lógico, en el muro sureste de la construcción 9 y que, por el contrario, este provista de su propio muro, aunque realmente adosado a aquél (Fig. 2); o que, en los espacios exteriores de la unidad de ocupación que estudiamos, la escoria recogida supere los $100 \mathrm{Kg}$. mientras que, por ejemplo, en el espacio al que abre su umbral la vivienda 14 no haya aparecido un sólo fragmento. Es más, no deja de ser notable, en el sentido de establecer una clara y exclusiva orientación metalúrgica a esta unidad, que en todo el resto del poblado no aparecieran más que dos o tres fragmentos de escoria.

Instalaciones interiores y materiales diferencian de forma evidente a esta unidad de ocupación de las otras que han sido excavadas en La Corona de Corporales; sin embargo muchas de sus características constructivas o la disposición espacial de algunos de los elementos que la integran son similares, por no decir idénticos, que en el resto. Para analizar esas semejanzas o diferencias, hemos reunido algunos datos en la tabla 1.

A la izquierda de la tabla vemos como el número de construcciones que forman la unidad de ocupación que ahora nos interesa no es ni may.or ni menor que el resto, por más que sea 
TABLA 1

LA CORONA DE CORPORALES. ESPACIOS CON SU FUNCIONALIDAD, SUPERFICIE UTIL Y EL NUMERO DE DIVERSOS HALLAZGOS RELACIONADOS CON LA ACTIVIDAD METALURGICA. LAS LINEAS SEPARAN LAS UNIDADES DE OCUPACION

\begin{tabular}{|c|c|c|c|c|c|c|c|c|}
\hline Espacio & Funcionalidad & $\begin{array}{c}\text { superf. } \\
\left(\mathrm{m}^{2}\right)\end{array}$ & $\begin{array}{l}\text { escoria } \\
\text { (kg) }\end{array}$ & bronce & hierro & $\begin{array}{l}\text { cerámica } \\
\text { escorf. }\end{array}$ & crisoles & $\begin{array}{l}\text { fragt. } \\
\text { hornos }\end{array}$ \\
\hline 11 & vivienda & 17,70 & - & 5 & 2 & - & - & - \\
\hline 12 & taller & 25 & 2 & - & 6 & - & - & - \\
\hline 13 & taller & 25 & 6 & 2 & 1 & 13 & - & 2 \\
\hline D & patio/taller & 20,30 & 3 & 3 & 3 & 33 & - & - \\
\hline E & patio & $>20$ & 64 & 3 & 4 & 50 & 5 & 3 \\
\hline $\mathrm{H}$ & basurero & $>20$ & 28 & 1 & 1 & 75 & 1 & 1 \\
\hline 1 & vivienda & 15 & - & - & - & - & - & - \\
\hline 5 & almacén & 21 & - & - & - & - & 1 & - \\
\hline A & patio & 4,70 & - & - & - & 1 & - & - \\
\hline 3 & vivienda & 17,80 & - & 1 & 2 & 3 & - & - \\
\hline 2 & anejo/viv. & 18 & - & - & - & - & - & - \\
\hline 4 & taller & 25 & - & - & - & - & - & - \\
\hline A & patio & 12,60 & - & 1 & - & - & - & - \\
\hline 6 & almacén & 10 & - & - & - & - & - & - \\
\hline 10 & viv./taller & 13 & - & - & 1 & 1 & - & - \\
\hline C & patio & 16,80 & - & - & - & - & - & - \\
\hline B & libre & $>10$ & 0,05 & - & - & - & - & $=$ \\
\hline \multirow{3}{*}{$\begin{array}{l}14 \\
15\end{array}$} & vivienda & 19 & - & - & - & - & - & - \\
\hline & almacén & $>14,50$ & - & - & - & - & - & - \\
\hline & exterior & $>3$ & - & 1 & 3 & - & - & - \\
\hline 8 & vivienda & $>17$ & - & 1 & 1 & - & - & - \\
\hline 9 & anejo/viv. & $>13$ & - & - & - & - & - & - \\
\hline
\end{tabular}

una de las mejor dotadas en este aspecto, siendo superada, por ejemplo, por la unidad de la vivienda 3 que esta compuesta por cuatro construcciones. Tampoco hay diferencias significativas en lo que se refiere a la forma de sus plantas, $o$ al hecho de que esas construcciones sean exentas o adosadas, o a la manera en que se articulan entre sí en el espacio. Sin embargo, entre sus construcciones no existe ninguna con funcionalidad de almacén, un tipo de dependencia caracterizado por carecer de umbral al nivel de la calle y que presenta unos anchos muros regulares y un cuidado y compacto pavimento. Estos almacenes, como vemos en la tabla citada, estan presentes en casi todas las unidades con dos a más construcciones. Por el contrario, es la única que presenta dos espacios destinados a taller, funcionalidad para la que se utiliza una sola construcción o ninguna en el resto de las unidades. De esta forma, aunque la composición de cada unidad de ocupación en lo que se refiere al tipo de espacio es muy diversa, queremos subrayar esa ausencia de almacén y esa presencia de doble taller en la unidad metalúrgica, circunstancia que la diferencia en especial de las demás.

Esta diferencia encuentra una expresión más clara cuando analizamos las superficies disponibles para cada funcionalidad en cada unidad de ocupación. Así, las viviendas poseen una superficie media de $16 \mathrm{~m}^{2}$, siendo precisamente la construcción 11 una de las más reducidas $\left(13,70 \mathrm{~m}^{2}\right)$, sobre todo cuando tenemos en cuenta que dos unidades de ocupación, las de las viviendas 3 y 8 , tienen anejos de habitación. Con ésto, el espacio destinado a la vida doméstica en la que ahora nos interesa se situaría entre los más bajos; y ello aún teniendo en 
cuenta la posibilidad de que al menos parte del taller de la construcción 12 se utilizase para tal fin. Lo que queremos hacer observar es que esta unidad metalúrgica no dispone de mayor cantidad de espacio para vivienda que las demás, considerando la disponibilidad de ese tipo de espacio como indicativo del "nivel de vida" de sus ocupantes. Por el contrario, es ella la que dispone de un mayor espacio construido destinado a taller, con $34 \mathrm{~m}^{2}$ frente a los 25 que posee, por ejemplo, la construcción 4 . Diferencia que no haría más que incrementarse si unimos a los anejos utilizados como taller aquellos espacios abiertos - patios, corrales, o instalaciones semicubiertas- bien acotados y caracterizados, claramente atribuibles a cada unidad de ocupación.

En resumen: la unidad de ocupación metalúrgica presenta, frente a un espacio comparativamente reducido dedicado a habitación, un valor alto -el más alto de todas las unidadespara el espacio destinado a trabajo, a la vez que carece del utilizable como almacén.

Esa necesidad de espacio disponible como taller o lugar de trabajo queda aún más de manifiesto si seguimos atendiendo a los datos presentados en la misma tabla, donde aparecen también los espacios exteriores claramente relacionados con cada una de las construcciones y dentro de sus correspondientes unidades de ocupación. Vemos así como la de la vivienda 11 domina o ejerce su influencia directa sobre los amplios espacios libres que la rodean, según prueban los hallazgos particularmente característicos antes citados. Espacios que pese a su amplitud no estuvieron destinados a la libre circulación, al contrario de lo que incluso sucede con otros más reducidos, por ejemplo el espacio B, que lleva en la tabla la calificación de «libre».

También en la tabla 1 hemos registrado algunos tipos de hallazgos de cada construcción y cada espacio. Son elementos significativos o determinantes en el contexto que interesa a este estudio. Sin embargo, podemos citar otros. Así, dentro del ajuar cerámico de la unidad metalúrgica, 10 vasijas aparecieron en la construcción/vivienda y ese ajuar no está en absoluto fuera de la media del resto de construcciones con igual funcionalidad. O también que la gran cantidad de material cerámico, fragmentado y disperso, aparecido en los cobertizos y espacios anexos de esta unidad, no es más que material utilizado en las tareas específicas de fundición. No ha de extrañar esta vinculación entre cerámica y metalurgia puesto que todavía se está empleando el tipo de vasija-horno para la transformación del mineral de cobre junto al de estaño. Este hormo primitivo, empleado desde época calcolítica, sigue siendo efectivo a pesar de su carácter rudimentario. Sin embargo, su escasa vida útil requiere el empleo frecuente de vasijas nuevas, y la recuperación de la masa metálica, su fragmentación. Como tal materia prima, se recogía y acumulaba en los espacios de influencia de la unidad. Esta utilización queda reflejada en la casilla de la tabla donde registramos los hallazgos de fragmentos cerámicos con escorificación o vitrificación, que pertenecieron generalmente a ollas de paredes no muy gruesas y con abundantes desgrasantes de pizarra en su pasta. Estos fragmentos con adherencias metálicas es un tipo de hallazgos exclusivo de los talleres y dependencias de la unidad metalúrgica, no apareciendo ni en su vivienda, ni en ningún otro lugar del poblado. Igual dispersión, como ya dijimos, presenta la escoria, aunque en algunos sectores puntuales de los espacios de vertido de la unidad metalúrgica, como en la esquina oriental de la construcción 12 , aparece amontonada.

También es notable la diferencia de objetos metálicos que presenta la unidad metalúrgica respecto a las demás, aunque siempre dentro de la parquedad con que este tipo de material aparece en el yacimiento. Sin embargo, una gran parte de ellos no son más que desechos casi inidentificables y de tamaño menudo, como trozos de clavos, placas, varillas, etc., que en su mayor parte son de hierro y más excepcionalmente de bronce. Estos últimos pudieran ser material amortizable.

Contrariamente a esta neta localización de la mayor parte de los hallazgos metálicos o relacionados con las labores de fundición, los hallazgos líticos (3) aparecen en el poblado con relativa profusión y lo hacen en casi todos los espacios y construcciones. Sin embargo su distribución espacial no deja, por su parte, de ser

(3) Recordaremos que el repertorio de utillaje lítico en La Corona consta de molinos, todos ellos del tipo barquiforme o plano, afiladeras, molederas, machacadores, esferas, fusayolas y algún otro útil de funcionalidad poco clara. 
significativa. En primer lugar destaca su ausencia en las construcciones calificadas de almacenes; en segundo término la frecuencia y variedad de este tipo de útiles, particularmente en la construcción 4 , unidas a otros testimonios permiten interpretarla como taller lítico. Junto a estas evidencias puede marcarse otra menos llamativa pero igual de significativa, como es la ausencia de molino (4) en la vivienda de la unidad metalúrgica frente a la presencia de al menos un ejemplar de este tipo en buen estado de uso en las otras unidades.

Las diferencias y similitudes que hemos ido marcando entre la unidad de ocupación metalúrgica y las restantes del poblado permiten presentarla con una clara orientación ocupacional. De esta forma, si se admite que las construcciones que denominamos "almacenes" son el reflejo de la producción de alimentos en el registro arqueológico de La Corona, la ausencia en la unidad objeto de este trabajo de este tipo de dependencia permitiría suponer que el trabajo metalúrgico eximía a sus ocupantes de la producción agropecuaria. En ese sentido, es interesante señalar una cierta relación entre el tamaño de los almacenes y la tendencia económica de la unidad a que pertenecen. Así se explicarían las reducidas dimensiones del almacén 6 , correspondiente a la unidad de ocupación de la vivienda 3 que, como ya hemos comentado, posee un taller de piezas líticas.

También es significativo que el espacio dedicado al trabajo en la unidad de ocupación que ahora nos interesa sea mucho más amplio que en las demás. La presencia de un doble taller, cuando las otras tienen sólo una o ninguna construcción dedicada a tal fin, y la de una serie de espacios utilizados para almacenar materia prima (desechos metálicos para reciclar, madera para combustible, etc.) o como vertedero (de escoria, cerámica escorificada, crisoles, etc.) parece indicar que sus ocupantes se dedicaban al trabajo metalúrgico a tiempo completo, sirviéndose de los excedentes agrícolas/ganaderos y otros productos de recolección del resto de los habitantes del poblado.

Esto nos lleva al artesano metalúrgico, figura recurrente en los estudios de las socieda-

(4) Solamente en la construcción/taller 12 apareció un fragmento de molino, pero inutilizado como tal y reutilizado como pequeña afiladera. des de la Edad del Hierro europea y al que tradicionalmente se le ha adjudicado un papel social significativo como especialista dotado de prestigio (Clarke, 1979: 319). No en vano la producción y control de objetos metálicos se consideran a menudo determinantes en el desarrollo de los procesos sociales. No parece ser este el caso del metalúrgico de La Corona de Corporales, cuyo prestigio no se refleja en ningún extremo del registro arqueológico. Como hemos visto, lo que se desprende del análisis funcional y espacial de nuestras excavaciones en el yacimiento no permite relacionarlo con una distribución diferencial de la riqueza: su espacio habitable, las características constructivas de su unidad de ocupación y, sobre todo, su ajuar doméstico son similares a los de las otras unidades. La única diferencia, el disponer de un mayor espacio de influencia, se explica perfectamente por las propias características de su trabajo. Puede concluirse por tanto que, al menos en aquellos aspectos que reflejan más directamente el nivel de vida en un poblado, la disponibilidad de riqueza o prestigio social de la unidad metalúrgica parece ser idéntica a las demás.

Otros autores, como Rowlands (1971), presentan a los metalúrgicos de las comunidades de base económica agropecuaria como especialistas, pero siempre a tiempo parcial. Es decir, prioritariamente ocupados en la producción de alimentos y desarrollando su trabajo especializado en momentos libres o lentos del ciclo agrícola. Tampoco esta imagen cuadra con los datos obtenidos en La Corona de Corporales, donde en la unidad metalúrgica sólo parece realizarse el trabajo especializado y a tiempo completo. En este sentido tampoco es aplicable la idea de Wells (1988: 26) de que una vez que la base de subsistencia de una sociedad esta asegurada se puede permitir que algunos de sus miembros se dediquen a actividades no relacionadas con ella. Según ésto, la mayor parte de estas comunidades prerromanas estarían formadas por agricultores que realizaban otras labores - como ésta de la producción de metal- sólo en su tiempo libre.

La figura de un artesano metalúrgico que desarrolla esa única actividad, según sugiere el registro arqueológico de La Corona, no nos parece, sin embargo, extraña en el tipo de sociedad que representan estos castros. Una 
producción suficiente para el abastecimiento de útiles metálicos al pequeño grupo humano que lo ocupa y que se intercambia por productos agrícolas dentro de esa misma comunidad, es un planteamiento que encaja muy bien con la sociedad cerrada y autosuficiente que define la arqueología para estas comunidades de astures prerromanos. Comunidades ajenas a conceptos de rentabilidad en términos modernos y que evidentemente se mantenían fuera de sistemas comerciales más amplios u organizados. Por otra parte la producción metálica, especialmente de hierro, necesaria para cubrir las necesidades de la comunidad, no es una tarea menor, y necesita gran cantidad de tiempo. Los cálculos experimentales para completar una fundición de hierro se sitúan en unas 12 horas (Nosek, 1985: 167-68), y la cantidad de metal obtenido no es grande dada la limitada capacidad de los hornos de la época. A ese tiempo hay que añadir la preparación y acondicionamiento del horno y el nada breve trabajo de forja posterior para dar forma al objeto. Además, la función utilitaria del hierro exige una producción continuada de sustitución y reparación de herramientas. También conviene considerar que el metalúrgico trabaja tanto el hierro para las herramientas, como el cobre/bronce para objetos personales y de adorno, por lo que su tiempo de actividad queda cubierto plenamente con esta tarea, a la que podrían añadirse labores extractivas, especialmente de mineral de cobre, cuya metalurgia parece ser más selectiva por el tipo de objetos a la que se dedica.

El alto grado de conservación del contexto real observable, producida por una destrucción súbita en La Corona de Corporales - aunque siempre dentro de las normales limitaciones de ese tipo de analítica espacial-, permite esas propuestas sobre la figura del metalúrgico y su ámbito de trabajo. El caso de El Castrelín, como ya apuntamos, es muy diferente. En este segundo castro la deposición de abandono obliga a interpretar, sobre todo, las conductas de rechazo implícitas en lo que suponemos fue un desalojo simultáneo de sus habitantes. Sin embargo, la fácil extrapolación del modelo de ordenación funcional del espacio de aquel castro a éste, la excavación de un vertedero, por decirlo así, especializado en metalurgia y algunos hallazgos especiales, como son, por ejemplo, unos moldes cerámicos de fundición para un determinado tipo de sítulas, nos permiten completar algunos datos sobre la materia de este trabajo.

En la figura 3 y en la tabla 2 vemos como es viable una determinación de las diversas unidades de ocupación en el sector excavado, así como la caracterización funcional de muchas de las construcciones que las componen. Sin embargo, ninguna de ellas puede claramente ser diferenciada como metalúrgica en virtud de sus componentes de ajuar o de su mobiliario. Sobre todo, porque la mayor parte de los espacios presentan entre sus hallazgos algún elemento relacionado con las labores metalúrgicas, ya sea en sus propios niveles de ocupación o en sus espacios exteriores de vertido. En este sentido El Castrelín está muy lejos de la expresiva dirpersión de elementos como la escoria, los fragmentos de crisol o la cerámica con adherencias metálicas o escorificada, en La Corona de Corporales.

Sin embargo, algunas construcciones presentan una relativamente abundante proporción de ese tipo de restos de fundicion. Así sucede, por ejemplo, con el taller 13, una pequeña dependencia que se adosa a la vivienda 1 en un momento posterior a la construcción de la citada vivienda y su almacén y próximo ya al del abandono del poblado. También esta pequeña construcción fue levantada con porterioridad a la formación del basurero especializado al que hemos hecho alusión y cuyos vertidos deben proceder de una unidad de ocupación próxima, aún no excavada.

El espacio utilizado como lugar de vertido por esa todavía no identificada unidad metalúrgica se situa entre el paramento interno de la muralla y la construcción 5. Una amplia superficie de la que parte, una vez colmatado el basurero, sirvió para ampliar la unidad de la construcción citada con la vivienda 7 y el anejo 4. Es decir, el vertedero no era utilizado como tal en la fase constructiva que representa el abandono del poblado. Circunstancia que, por un lado dificultará su adscripción como espacio de influencia a una determinada unidad de ocupación, pero que, por otro, ha permitido que llegue a nosotros íntegro.

El vertedero $G$ es un espacio de cierta duración que ocupa una extensión de algo más 
TABLA 2

EL CASTRELIN DE SAN JUAN DE PALUEZAS. ESPACIOS CON SU FUNCIONALIDAD, SUPERFICIE UTIL Y NUMERO DE DIVERSOS HALLAZGOS RELACIONADOS CON LA ACTIVIDAD METALURGICA. LAS LINEAS SEPARAN LAS UNIDADES DE OCUPACION

\begin{tabular}{|c|c|c|c|c|c|c|c|c|c|}
\hline Espacio & Funcionalidad & $\begin{array}{c}\text { superf. } \\
\left(\mathrm{m}^{2}\right)\end{array}$ & $\begin{array}{c}\text { escoria } \\
\text { (kg) }\end{array}$ & bronce & hierro & cer. escorf. & crisoles & f. hornos & f. moldes \\
\hline 3 & vivienda & $>6,50$ & - & - & - & - & - & - & - \\
\hline 2 & almacén & 9,60 & - & - & - & - & - & - & - \\
\hline B & patio/corral & 10 & 0,07 & 1 & 3 & 33 & - & - & - \\
\hline $\mathrm{C}$ & exterior & $>3$ & 0,02 & 1 & 1 & 3 & - & - & - \\
\hline 1 & vivienda & 10,20 & 0,03 & - & 3 & 3 & - & - & - \\
\hline 6 & almacén & 8,40 & - & - & 2 & - & - & - & - \\
\hline E & patio & 3,60 & 1,50 & - & - & 2 & - & - & - \\
\hline 13 & taller & $>7$ & 2,50 & 4 & 3 & 30 & - & 1 & - \\
\hline 7 & vivienda & $>9$ & 0,50 & - & - & - & - & - & - \\
\hline 4 & anejo & 7,50 & - & 2 & 1 & - & - & - & - \\
\hline 5 & anejo & 13 & 0,30 & - & - & - & - & - & - \\
\hline $\mathrm{F}$ & patio/taller & 24 & 0,05 & 1 & - & 5 & - & - & - \\
\hline $\mathrm{H}$ & patio & 12,80 & 0,50 & 3 & 3 & 9 & 2 & - & 3 \\
\hline 10 & vivienda & 9 & - & - & - & - & - & - & - \\
\hline 11 & almacén & $>4$ & - & - & - & - & - & - & - \\
\hline 12 & anejo & $>8,50$ & - & - & - & - & - & - & - \\
\hline I & anejo & $>3$ & - & - & - & - & - & - & - \\
\hline G & vertedero & 12 & 13,70 & 24 & 33 & 148 & 9 & 13 & 114 \\
\hline A & libre & $>58$ & 9,40 & 7 & 17 & 8 & 6 & 4 & - \\
\hline
\end{tabular}

de $12 \mathrm{~m}^{2}$ y ostenta $0,70 \mathrm{~m}$ de potencia máxima. Fue rellenando una zona deprimida, por lo que solamente estuvieron sujetos a fenomenos de arrastre los niveles superiores de uno de sus extremos, donde el terreno buza naturalmente hacia el Norte. Las características de su deposición indican una formación lenta, con aportaciones ocasionales de cierto volumen y periódicos vertidos de ceniza purulenta y blanquecina, producto de una combustión larga y que bien pudieran provenir de la limpieza de hornos u otras instalaciones metalúrgicas. También son abundantes las inclusiones carbonosas y de arcilla rojiza. Además de esta clara dinámica de formación, es interesante la fuerte entidad de los productos en él desechados que revelan una marcada especialización: junto a una relativa abundancia de restos de fauna, todos los materiales proceden exclusivamente de labores metalúrgicas, sean crisoles, toberas, fragmentos de hornos, cerámicas escorificadas o "gotas" de metal desaprovechadas de la fundición. Asimismo es notable la presencia de escoria (en una cantidad cercana a los $14 \mathrm{Kg}$.), de pequeños objetos de bronce y de fragmentos de moldes de fundición cerámicos. Estos restos pertenecen unos a la metalurgia del hierro y otros a la de base cobre, al igual que ocurría en La Corona de Corporales.

El mero hecho de la funcionalidad de vertedero de ese espacio $\mathrm{G}$ inhabilita toda comparación con los reflejados en la tabla 2, dedicados a vivienda, trabajo o almacén. Sin embargo contamos con otros basureros que permiten esa comparación. En todos ellos los restos de fundición o de escoria vertidos son insignificantes, a excepción quizás del espacio A que, a efectos de contraste, hemos reflejado en dicha tabla. Aunque no se trata estrictamente de un vertedero -es un espacio libre de uso común- y su depósito es producto de todo el período de ocupación de El Castrelín, el hecho de que fuese utilizado recurrentemente como lugar de vertido de desperdicios, permite esa comparación: el montante de escoria, relativamente cercana a la recogida en el basurero metalúrgico, queda 
minimizada por los escasos fragmentos de cerámica escorificada y otros restos metálicos o de fundición, evidenciando la especialización del espacio G. Esa especialización del lugarde vertido permite plantear, lógicamente, la del lugar de trabajo de donde proceden los desechos en él contenidos, reproduciéndose así el modelo de La Corona en el que una unidad de ocupación se dedica exclusivamente a la metalurgia. De esta manera, son extensibles a este segundo castro las precisiones que sobre el artesano que la ocupaba que hemos comentado más arriba.

\section{LA TECNOLOGIA Y LA PRODUCCION AUTOSUFICIENTE DE LA ACTIVIDAD MINEROMETALURGICA PRERROMANA}

En los dos yacimientos los materiales hallados en estos espacios, muy distintos en funcionalidad pero producto ambos de una misma actividad metalúrgica, ilustran aspectos de la producción y de la tecnología del metal empleadas por estas poblaciones inmediatamente anteriores a la presencia romana en la zona. Y lo que destaca en primer lugar es la escasa presencia de útiles o restos de fundición de bronce frente al número de útiles $\mathrm{y}$, sobre todo, de escoria de hierro. Esto indica una manera muy distinta de acceder y producir uno y otro metal. Veamos en primer lugar el bronce.

La metalurgia del cobre y sus aleaciones se desarrolló en ambos poblados de forma autosuficiente, y con un carácter de abastecimiento local poco especializado en la producción. La presencia de materiales que cubren todas las fases del trabajo metalúrgico permite reconstruir con cierta fiabilidad la tecnología empleada, gracias a la información complementaria que nos ofrecen los análisis cuantitativos realizados a una muestra de esos materiales. Las composiciones de algunas piezas de La Corona de Corporales fueron publicadas oportunamente (Fernández-Posse y Sánchez Palencia, 1988: 251), sin embargo, circunstancias ajenas a nuestra voluntad han impedido aumentar la muestra analizada; del Castrelín, por el contrario, se han realizado 70 análisis. Aunque gran parte de los datos manejados corresponden, pues, a este último yacimiento, las similitudes apreciadas en los materiales estudiados permiten suponer una base tecnológica idéntica que incluso puede ser extrapolable de forma general a otras zonas vecinas de la Cultura Castreña.

El primer rasgo que apunta hacia el autoabastecimiento y a una producción de carácter local es el tipo de horno empleado en la reducción del mineral. El uso de vasijas, sin elementos diferenciadores de otras producciones cerámicas, como hornos, a pesar de utilizar otros tipos más complejos necesarios para la producción del hierro, indica el poco esfuerzo e interés que se dedica a esta tarea. La vasija-horno es el sistema más primitivo y rudimentario para realizar la transformación inicial del mineral, y se puede emplear en cualquier parte ya que no requiere trabajos de preparación o áreas de acondicionamiento especiales. En estas vasijas, en ocasiones, se obtiene tras el proceso cobre metálico, pero también se mezcla mineral de cobre con mineral de estaño para realizar una reducción conjunta, y obtener de este modo la aleación de bronce. Este modo de alear metales es también el más simple, pero tiene el inconveniente de que permite un menor control sobre las proporciones de los metales y la calidad de la aleación.

De esta tarea de transformación realizada en los poblados se deduce el trabajo directo con los minerales, tanto de cobre como de estaño, sobre cuyos recursos disponibles se hablará más adelante. Por tanto, no puede proponerse comercio de metal en bruto. Las barritas-lingote de sección romboidal o cuadrada recogidas en ambos yacimientos, dos de La Corona de Corporales y seis del Castrelín - de las que podemos ver algunos ejemplos en la figura $4-$, no tienen una función comercial, sino que se usan para cubrir las necesidades del trabajo metalúrgico local. Lo poco normalizado de sus formas, tamaños, pesos y aleaciones expresan lo lejos que está la metalurgia de estas poblaciones de un sistema de circulación del bronce organizado y a cierta escala, en donde tales lingotes pudieran tener un valor de cambio. Por el contrario, son más propios de un medio económico poco integrado y de corto alcance, en donde representarían una forma cómoda de almacenar el metal. Estas barras pueden fabricarse con el metal bruto obtenido de la transformación del mineral, o más probablemente mediante el reciclaje de piezas manufacturadas inutilizadas, que se refunden juntas y el metal obtenido se alma- 


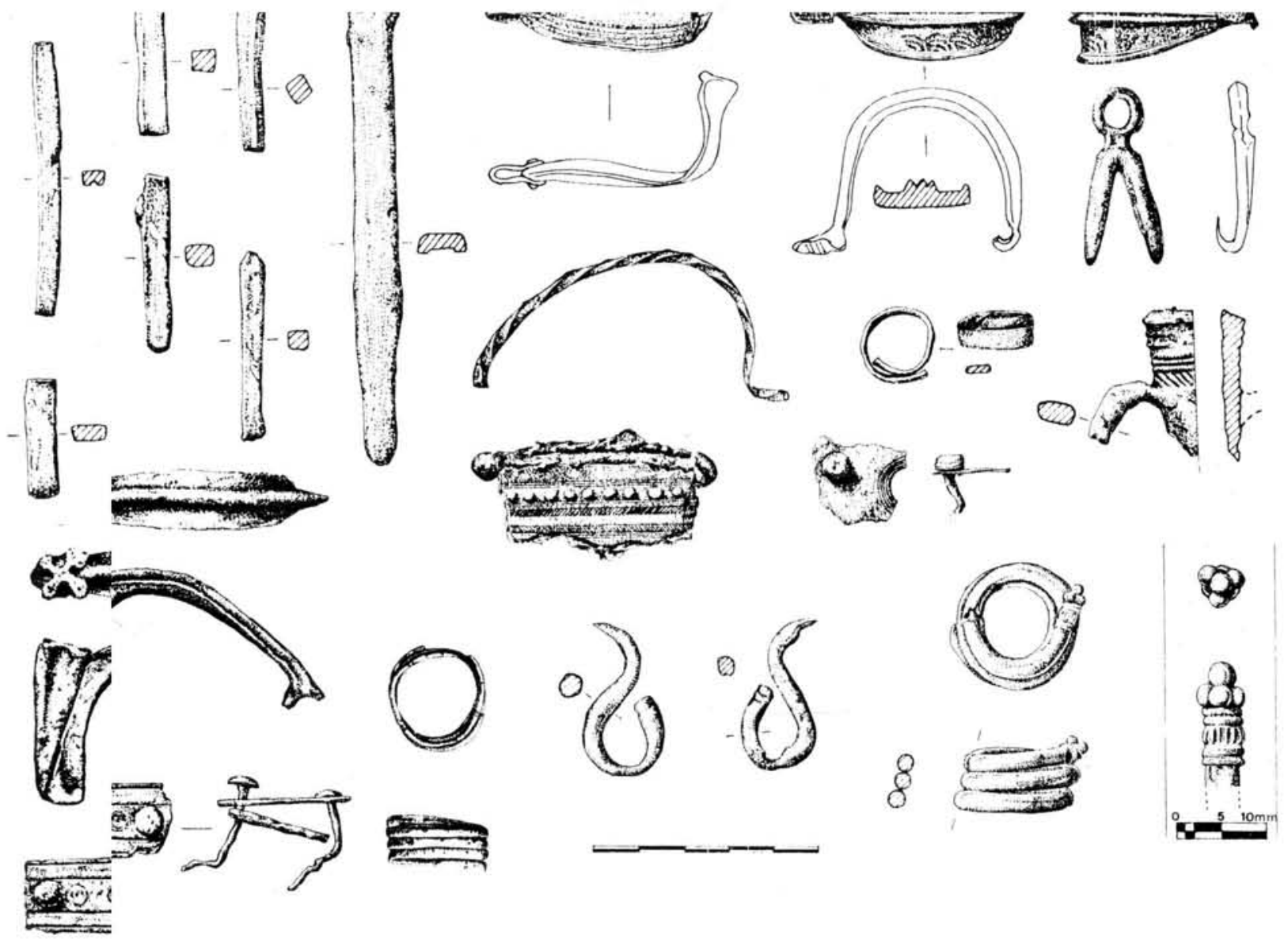

Diversos objetos de bronce aparecidos en El Castrelín de San Juan de Paluezas y en La Corona de Corporales.

Fig. 4. guarda en forma de estas barras. La tización del metal cobra sentido cuando cena orva que aparece en los espacios metalúrreamor $2 s c r i t o s$ diseminado como objetos menuse obses o menos fragmentados y siempre usagicos didemás, si aceptamos esta práctica de dos máechar el metal, no ha de extrañarnos dos. A La Corona de Corporales las piezas de reapror no sobrepasen demasiado la docena, de que en, además, diez pertenecen a la unidad de bronce ión metalúrgica. Esta mínima presencia

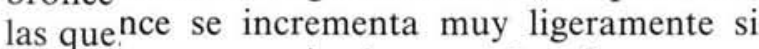
ocupac os una serie de pequeños fragmentos de bro ificables y los dos pequeños lingotes. En añadim relín, el número de piezas es algo más inident ${ }^{\circ}$ ro de igual forma la mayor parte son

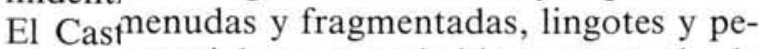
alto, pematerial reaprovechable cuyo estado de piezas t tación no permite saber a que tipo de objeto queño

fragmen pertenecieron. Casi todas proceden del vertedero especializado. Evidentemente el número de hallazgos de bronce en cada castro ha de ponerse en relación, además de con la ya citada diferente funcionalidad de los espacios que los han proporcionado, con la superficie excavada en cada yacimiento y, sobre todo, con sus muy diferentes tipos de abandono. No hay que olvidar que en La Corona tenemos "todo" el bronce de que se disponía en el momento inmediato a su destrucción, y en El Castrelín fue, como material preciado que era, presumiblemente retirado al producirse su desalojo; lo que manifiesta una mayor riqueza relativa de este último castro. Por otro lado, la notable presencia de material de desecho - todo se reciclaba- en ambos yacimientos, indica hasta que punto era valorado este metal en la economía de estos asentamientos prerromanos. 
Frente a ese corto número de piezas de bronce, sorprende lo que podríamos denominar su variabilidad. Además y con frecuencia, suelen ser objetos de adorno personal de aceptable factura, como plaquitas finamente decoradas, asas de vasijas, anillos y aretes o alguna fíbula (Fig. 4). Es decir, el bronce ha trascendido lo utilitario para reducirse a un papel de cierto prestigio, que adquiere tanto por la presencia del hierro para la fabricación de útiles y herramientas, como por su propia escasez.

La composición de los objetos es, también, muy variada, incluso dentro del mismo tipo de pieza, lo que indica una falta de homogeneidad o criterio de fabricación general, que debe obedecer más a criterios socioeconómicos que tecnológicos. Contamos con 22 análisis de objetos del Castrelín y tres de La Corona (ver Apéndice), excluidas las barras-lingote. Si tomamos como ejemplo los anillos y aretes, elementos claramente dedicados a una función de adorno personal, de los 5 analizados en El Castrelín tres son de bronce y dos de cobre. Entre los anillos de bronce, con diferente proporción de estaño, uno de ellos lleva también impurezas muy altas de arsénico y antimonio, y otro puede considerarsae bronce plomado; de los fabricados en cobre, uno es en realidad cobre arsenicado. Esta diversidad podría explicarse por el diferente tipo de metal utilizado, es decir, o metal nuevo, o fabricado a partir del metal reciclado entregado por el cliente, o de la disponibilidad de estaño en función de las posibilidades del usuario o comprador del objeto. En el caso de los fragmentos laminares, podría pensarse a tenor de los análisis que existe una mayor normalización en la producción, con el empleo de bronces binarios $\mathrm{Cu}-\mathrm{Sn}$ en torno al $10-15 \%$ Sn, sin embargo, tres de las cinco piezas clasificadas de este modo se recuperaron en el mismo contexto -el Vertedero G- y deben ser en realidad fragmentos de una misma pieza destinada a la refundición. Por tanto, si las consideramos como una sola, tendríamos dos láminas de bronce y una de cobre, criterio insuficiente para establecer una norma o tendencia. El resto de materiales analizados de ambos yacimientos son piezas sueltas, unas de cobre con arsénico y/o antimonio, algún bronce pobre difícil de clasificar, otros bronces binarios o bronces plomados con proporción variable de estaño y plomo. En resumen, lo más destacado del conjunto de análisis es la variación en las composiciones y el uso de cobre o cobre arsenicado $\mathrm{y} / \mathrm{o}$ antimoniado en considerable proporción entre los materiales del Castrelín para las fechas en que nos encontramos y en el tipo de objeto en que se usan.

Finalmente cabe comentar a favor de la fabricación local de las piezas, la relación directa que se puede hacer entre las composiciones de los objetos elaborados, y las producciones que se obtendrían de los restos de actividad metalúrgica recuperados. En ellos aparecen también una gran diversidad de opciones, desde adherencias de vasijas-horno donde se procesó cobre con arsénico y antimonio, otras de bronce con elevadas impurezas de arsénico y antimonio, o restos de fundición metálicos de horno y gotas de crisol de cobre, bronce binario y ternario. Todas las composiciones de los objetos analizados tienen más o menos una relación próxima con alguno de los restos metalúrgicos de los poblados, por lo que es asumible sin ningún tipo de riesgo su manufactura local.

Los procedimientos seguidos en el trabajo metalúrgico que se acaba de describir resultan muy propios de la organización económica y social que atribuimos a estos artesanos astures prerromanos que trabajaban de forma independiente en comunidades también independientes, sin que ninguna de ellas fuera un centro productivo que surtiese, siquiera de materia prima, a las demás.

Hasta ahora hemos hablado de una metalurgia exageradamente local en donde la producción metálica del bronce no alcanza siquiera la escala regional. Sin embargo, es precisamente esta actividad la que nos va a permitir situar la zona que estudiamos en un contexto cultural más amplio. Ya hemos mencionado la existencia de numerosos fragmentos de un determinado tipo de molde cerámico para fabricar sítulas en el Vertedero especializado de El Castrelín (Lám. I) que, aunque no aparecen en La Corona de Corporales, sí lo hacen en una amplia zona gallega. Lo primero se acomoda bien a la organización poco integrada de estas comunidades; lo segundo nos está hablando de unos contactos e intercambios en el seno de un ámbito regional extenso, ya que este tipo de sítula, además de unas características fijas e 
APENDICE

MATERIALES DEL CASTRELIN DE SAN JUAN DE PALUEZAS ANALISIS POR XRF (\% EN PESO)

\begin{tabular}{|c|c|c|c|c|c|c|c|c|c|c|c|}
\hline ANALISIS & OBJETO & $\mathrm{Fe}$ & Ni & Cu & $\mathrm{Zn}$ & As & Ag & Sn & Sb & $\mathrm{Pb}$ & INVENTARIO \\
\hline A3335 & Adherencia cerámica & 6.18 & 6.57 & 70.43 & nd & 8.06 & 0.091 & 0.68 & 3.332 & 2.48 & CSP.1A. 90.44 \\
\hline PA3336 & Adherencia cerámica & 72.51 & nd & nd & nd & nd & 5.599 & 1.18 & 0.289 & 18.23 & .5 .4 \\
\hline PA3360 & Adherencia cerámica & 20.35 & nd & 18.10 & nd & nd & 25.49 & 17.66 & 0.228 & 13.55 & CSI \\
\hline PA3365 & Adherencia cerámica & 1.13 & 0.35 & 19.81 & nd & nd & 15.34 & nd & nd & 63.34 & CSP.1B. 90.45 \\
\hline PA3366 & Adherencia cerámica & 2.25 & 0.82 & & nd & nd & 6.957 & nd & nd & 75.20 & CSP \\
\hline PA3367 & Adherencia cerámica & 0.77 & 0.45 & 33.03 & nd & nd & 33.96 & nd & nd & 31.01 & .45 \\
\hline A3742A & Adherencia cerá & 2.54 & 11.77 & & nd & 1.18 & 0.027 & 22.50 & 2.369 & & \\
\hline A3742B & Adherencia cerá & 28.26 & 3.85 & 66 & nd & 2.18 & 0.051 & & 0.434 & 15.51 & \\
\hline & Adherencia cerámica (bor) & 9.46 & nd & 13.75 & nd & nd & nd & 24.30 & 1.173 & & $3 \mathrm{~A}$ \\
\hline 1B & Adherencia cerámica (par) & 38.90 & nd & 12.50 & nd & nd & nd & 20.78 & 0.579 & 72 & 3A \\
\hline 3 & rencia re & 30.55 & 1.11 & 29.96 & nd & 1.83 & nd & 25.21 & 1.713 & 9.14 & $3 B$ \\
\hline A3 & A & 11 & nd & 98.78 & nd & 0.39 & nd & 0.20 & 0.082 & nd & cs \\
\hline 29 & la (frag.) & 0.37 & 0.27 & 69.75 & nd & nd & 0.113 & 25.01 & 0.432 & 3.34 & $17 \mathrm{~W}$ \\
\hline 7 & An & 0 . & 0.11 & & nd & 1.78 & 0.448 & 0.06 & 0.131 & nd & \\
\hline A. & & 0.56 & & 0 & nd & nd & 51 & 21. & 0.149 & 3.10 & \\
\hline$A 3$ & 0 & 0.95 & 0.44 & 76.50 & nd & 0.94 & 21 & 17 & 1.655 & 1.47 & \\
\hline$A^{3}$ & 0 & 1.46 & 0.41 & 97.03 & nd & 0.58 & 0.090 & 0.07 & 0. & 0.28 & \\
\hline$A^{3}$ & Aplique circular & 0.49 & 0.36 & 97.11 & nd & 0.43 & 0.150 & 1.01 & 0.447 & nd & 63 \\
\hline 0 & Aplique circular & 0.19 & 0.28 & 97.80 & nd & 0.09 & 0.091 & 0.51 & 0.709 & 0.33 & 63 \\
\hline$A^{3}$ & Arete & 0.13 & 0.42 & 86.65 & nd & nd & 0.102 & 10.94 & 0.623 & 1.13 & .63 \\
\hline A3 & Barrita sec. & 0.12 & nd & 97.43 & nd & 0.29 & 0.110 & 0.18 & 1.139 & 0.74 & $.82 B$ \\
\hline & ita sec. & 0.29 & 0.10 & 98 & nd & nd & 18 & 0 . & 0.279 & 0.49 & \\
\hline A. & Barrita sec. cu & 0.10 & 0.14 & 98 & nd & nd & 0.055 & 0.16 & 1.125 & 0.10 & \\
\hline 6 & Barrita sec. rectangular & 0.50 & 0.23 & 84.86 & nd & 0.57 & 0.065 & 12.38 & 0.164 & 1.22 & CS \\
\hline 3 & Cincel (frag.) & 0.13 & 0.05 & 97.58 & nd & nd & 0.047 & 1.83 & 0.174 & 0.19 & c \\
\hline 8 & ? ? & 0.13 & nd & 97.89 & nd & nd & 0.109 & 0.44 & 0.864 & 0.21 & c \\
\hline & ol (Fra & & nd & & nd & nd & nd & 38. & nd & 10.55 & 17EA \\
\hline & ol (Fré & 7 & nd & & nd & nd & nd & 10 & 0.450 & 7.89 & cs \\
\hline & ol (Fr & & nd & 45 & nd & nd & nd & 1 & 0.168 & 5.12 & \\
\hline A & ol & & nd & 3 & nd & nd & 0.052 & 3 & 0.191 & nd & \\
\hline B & Crisol (Fr & 1 & 3.95 & 46. & nd & nd & 12 & & 0.8 & 10.42 & \\
\hline PA3 & Crisol ( Fr & 6 & nd & 4 & nd & nd & 0.060 & 57 & 0.024 & 2.62 & \\
\hline $7 \mathrm{~A}$ & Crisol (Frag.) & .13 & 0.62 & 39.92 & nd & nd & 0.023 & 38.83 & 4.881 & 3.60 & 2C \\
\hline 78 & Crisol (Frag.) & .68 & 0.92 & 30.80 & nd & nd & 0.006 & 47.73 & 2.195 & 7.67 & $52 \mathrm{C}$ \\
\hline 'C & sol (Fra & .29 & 1.50 & 65 & nd & nd & 0.103 & 18. & 1.562 & 3.55 & $62 \mathrm{C}$ \\
\hline A & Crisol (Fra & 3 & 0.71 & 12 & nd & nd & nd & 3 & 0.295 & 24.34 & 77 \\
\hline & sol (Fri & & 1.37 & & nd & nd & $\mathrm{nc}$ & & 0. & 34 & C \\
\hline 47 & ol (Fra & 37 & 0.72 & & nd & nd & nd & 39 & 0.7 & 9.09 & C \\
\hline & id & .84 & 1.10 & & nd & nd & 0.011 & & 0. & & \\
\hline & a Li & 7 & 1.60 & 6 & nd & nd & 87 & & & 77 & \\
\hline & e) & 7 & nd & 8 & nd & 1.46 & 27 & 2 & & 1.21 & $7 \mathrm{w}$ \\
\hline PA3 & erminado & 0.50 & 0.12 & 94.90 & nd & 1.04 & 0.258 & 0.81 & 1.156 & 1.13 & $17 \mathrm{~W}$ \\
\hline PA3720 & erforaciones & 0.60 & 0.17 & 78.59 & nd & nd & 0.041 & 20.55 & 0.048 & nd & $82 \mathrm{~A}$ \\
\hline PA3741 & Lamina perforada & 0.09 & 0.19 & 85.17 & nd & 0.07 & 0.029 & 11.94 & 0.420 & 2.07 & 63 \\
\hline ASI & na & 0.36 & 0.14 & 85 & nd & nd & 0.008 & 13.94 & 0.004 & 0.09 & $\operatorname{cs}$ \\
\hline 39 & na (fra & 0.07 & 0.04 & 86 & $\mathrm{n}$ & 0.44 & 0.072 & 10.05 & $0.3+3 x+3$ & 1.81 & C \\
\hline & a $(f r a$ & 10 & 0.44 & & nd & 17 & 0. & 9.65 & 0 . & 0 . & \\
\hline$A 3$ & de & & 0.26 & & $\mathrm{n}$ & 0.40 & 0. & 25.06 & 0. & 4.30 & \\
\hline & a $\mathrm{F}-2-2$ & & 10 & & nd & d & 52 & 1.27 & & 0.24 & \\
\hline & 8 & 0.40 & nd & 75.16 & nd & id & 0.046 & 20.80 & 0.214 & 3.38 & \\
\hline & Jita con estrías & 0.01 & nd & 99.50 & nd & 0.32 & 0.060 & nd & 11 & nd & \\
\hline & che & 0.35 & 0.49 & 76.21 & $\mathrm{n}$ & nd & 0.202 & 14.60 & 2.898 & 5.73 & 63 \\
\hline PA3 & Resto fundic & 0.53 & nd & 80.18 & nd & nd & 0.016 & 17.91 & 0.070 & 0.55 & Cs \\
\hline PA3697 & Resto fundición crisol & 0.15 & 0.15 & 99. & nd & 0.32 & 0.004 & 0.08 & 0.011 & nd & OB \\
\hline A & Resto fundición crisol & 0.60 & 0.34 & 72 & $n$ & nd & 0.124 & 22. & 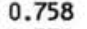 & 2.94 & cs \\
\hline 5B & Resto fundición $\mathrm{cr}$ isol & 0.66 & 0.50 & 77 & $n$ & nd & 0. & 1 & 0.574 & 2.14 & C \\
\hline & Resto fundic & 01 & 0. & 58. & $\mathrm{n}$ & nd & 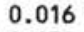 & 28 & 0.120 & 11.09 & \\
\hline A & Resto fundición crisol & 0.12 & 0.14 & 96 & nd & 0.65 & 0.058 & 1. & 0.329 & 0.65 & $\operatorname{cs}$ \\
\hline & Resto fundi & 0 . & 0.69 & 88.63 & nd & 1.15 & 0.022 & 0.1 & 8.146 & 0.65 & $.62 / 64$ \\
\hline & dición crisol & 3 & 0.77 & 78.02 & nd & 1.48 & 0.097 & 14.63 & 0.533 & 4.33 & CSP. \\
\hline & Resto fundición horno & 88 & 0.44 & & nd & nd & 0.121 & 43.85 & 2.3 & 7.22 & CS \\
\hline 4B & Resto fundición horno & 1 & 0.45 & 44. & nd & nd & 0.076 & 42.03 & 1.986 & 5.03 & CSP. \\
\hline $4 \mathrm{C}$ & Resto fundi & 3.63 & 0.09 & 52.56 & nd & nd & 0.084 & 37 & 1.700 & 4.33 & $79 \mathrm{~A}$ \\
\hline & Resto fundi & 1.67 & 0.36 & 55. & nd & 1.44 & 0.057 & & 1.500 & 4.26 & $\operatorname{CSP}$ \\
\hline & Resto fundi & 0.98 & 0.20 & & $\mathrm{n}$ & nd & 0.065 & & 0.5 & 2.41 & 164 \\
\hline & Resto fundi & 0.5 & 0.12 & 83. & nd & nd & 0.044 & & 0.225 & 1.35 & $52 / 64$ \\
\hline & Resto fundición horno & & 0.21 & 85.07 & $\mathrm{n}$ & 0.17 & 0.033 & & 0.070 & & \\
\hline & Resto fundición ho & 2.96 & 0.4 & 47.81 & $n$ & nd & nd & & & & CSP.1C \\
\hline & Resto fundi & & 0.89 & 26.1 & nd & nd & nd & 60.91 & 0.632 & 5.08 & CSP.10 \\
\hline & & & & .75 & Da & 0.71 & 0.110 & 9.01 & 0.639 & 1.47 & .63 \\
\hline
\end{tabular}

T. P., n 50, 1993 
MATERIALES DE LA CORONA DE CORPORALES ANALISIS POR XRF (\% EN PESO)

\begin{tabular}{|c|c|c|c|c|c|c|c|c|c|c|c|}
\hline ANALISIS & OBJETO & $\mathrm{Fe}$ & $\mathrm{Ni}$ & $\mathrm{Cu}$ & $\mathrm{Zn}$ & As & $\mathrm{Ag}$ & Sn & $\mathrm{Sb}$ & $\mathrm{Pb}$ & INVENTARIO \\
\hline PA0467A1 & Adherencia cerámica & 7.55 & $\cdots$ & 51.95 & nd & 0.41 & 0.034 & 22.18 & 0.596 & 15.89 & CC- 106 \\
\hline PA0453B & Adherencia cerámica & 35.3 & nd & 15.44 & nd & nd & nd & 43.48 & 0.290 & 2.58 & CC -30 \\
\hline PA0420 & Barrita sec. cuadrada & & 0.56 & 72.06 & nd & nd & 0.078 & 22.42 & 0.404 & 2.01 & CC -182 \\
\hline PA0423 & Espiral & 0 & 0.60 & 48.03 & nd & 1.39 & 0.135 & 38.55 & 1.105 & 8.24 & CC -127 \\
\hline PA0422 & Gancho & 0.97 & 0.89 & 70.56 & nd & 1.52 & 0.105 & 18.32 & 0.707 & 3.72 & CC-018-2 \\
\hline PA0421 & Pieza con asa & 0.31 & 0.61 & 59.34 & nd & nd & 0.072 & 25.96 & 1.338 & 10.16 & $\mathrm{CC}-0$ \\
\hline PA0466A & Resto fundición (metal) & 0.23 & 0.24 & 23.10 & nd & 0.46 & & & 0.811 & 42.90 & $C C-D-013$ \\
\hline PA0466B & Resto fundición (metal) & 2.77 & 0.55 & 42.01 & nd & 0.81 & & 44.52 & 0.327 & 7.71 & $C C-D-013$ \\
\hline PA0 466C & Resto fundición (metal) & 0.38 & nd & 55.06 & nd & nd & 0.218 & 30.29 & 0.903 & 10.03 & $C C-D-013$ \\
\hline
\end{tabular}

MATERIALES DEL CASTRO DE ORELLAN ANALISIS POR XRF (\% EN PESO)

\begin{tabular}{|c|c|c|c|c|c|c|c|c|c|c|c|}
\hline ANALISI & OBJETO & $\mathrm{Fe}$ & $\mathrm{N}$ & $\mathrm{Cu}$ & $\mathrm{Zn}$ & As & $\mathrm{Ag}$ & Sn & $\mathrm{Sb}$ & $\mathrm{Pb}$ & INVENTARIO \\
\hline 515 & Aguja de Hebilla & 0 & 0.39 & 62.78 & 5.57 & 0.00 & 0.559 & 10.03 & 0.347 & 19.33 & CO.2D \\
\hline 22 & Boton de fíbula & & & 87 & nd & & 0 & 22.16 & 0.230 & & $\mathrm{CO}$ \\
\hline 21 & Fragmento filiforme & & 0 & 77.86 & nd & 0. & 0.043 & 20.79 & 0.051 & 0.19 & Co. \\
\hline 27 & Lámina & D & 0.00 & 84.49 & nd & 0.00 & 0.023 & 14.17 & 0.050 & 0.92 & Co. \\
\hline 16 & Placa perforada & 0.42 & 0.00 & 88.41 & nd & 0.00 & 0.071 & 10.15 & 0.336 & 0 . & Co. \\
\hline & Placa perforada & & 6 & 90.84 & 0.40 & 0.00 & 0.033 & 7.45 & 0.077 & & $\mathrm{co.2}$ \\
\hline 23 & Placa perforada & & 0.00 & 88.84 & nd & 0.00 & 0.044 & 10.68 & 0.015 & & Co.2 \\
\hline PA3618 & Remache circular & 0.39 & 0.00 & 81.84 & 16.61 & 0.00 & 0.086 & 0.57 & 0.079 & 0.41 & Co.2D.91.10 \\
\hline
\end{tabular}

incluso repetitivas, ofrece una amplia dispersión en castros del Occidente gallego y portugués (Carballo, 1983) y empieza ahora a documentarse en el territorio astur. Lo que Renfrew (1986: 1) ha denominado «sistema de interacción entre iguales", resulta particularmente apropiado a esta situación prerromana de contactos entre castros absolutamente independientes. Pero quizas sea posible definir o afinar el carácter de esa interacción.

Las sítulas son una clase muy especial de objeto, siempre con una connotación ritual y de prestigio. Eso, que es quizás también el motivo de que el tipo esté tan normalizado, ayuda a entender que estamos ante una interacción en el dominio de lo simbólico o de lo religioso. Sobre todo cuando vemos hasta que punto son iguales los moldes de sítulas de El Castrelín y el aparecido en el Castro da Forca - por citar un ejemplo de castro gallego bien y recientemente publicado-, cerca de la desembocadura del río Miño (Carballo, 1987: fig. 50). Y contrastamos esa similitud con el hecho de que en ese mismo castro gallego, y en unas fechas incluso algo más antiguas que las de El Castrelín, hay molinos circulares que no aparecen en los castros prerromanos leoneses excavados por nosotros, donde son siempre planos y, por lo tanto, mucho menos rentables. Los contactos o intercambios parecen, por lo tanto, no tener lugar en el más simple nivel de los medios de producción agropecuaria; es decir, en un tipo de objeto tan abundante, utilitario y cotidiano como son los molinos de mano, pero sí en esa manufactura de especial significación y difícil factura que son las sítulas. La interacción entre estas poblaciones castreñas del Noroeste parece, pues, obedecer a conductas diferenciales según el ámbito de los objetos, quedando patente en la esfera simbólica-religiosa, como ya apuntamos en alguna otra ocasión (Fernández-Posse y SánchezPalencia, 1988: 240), pero no en la tecnológica o metalúrgica. 

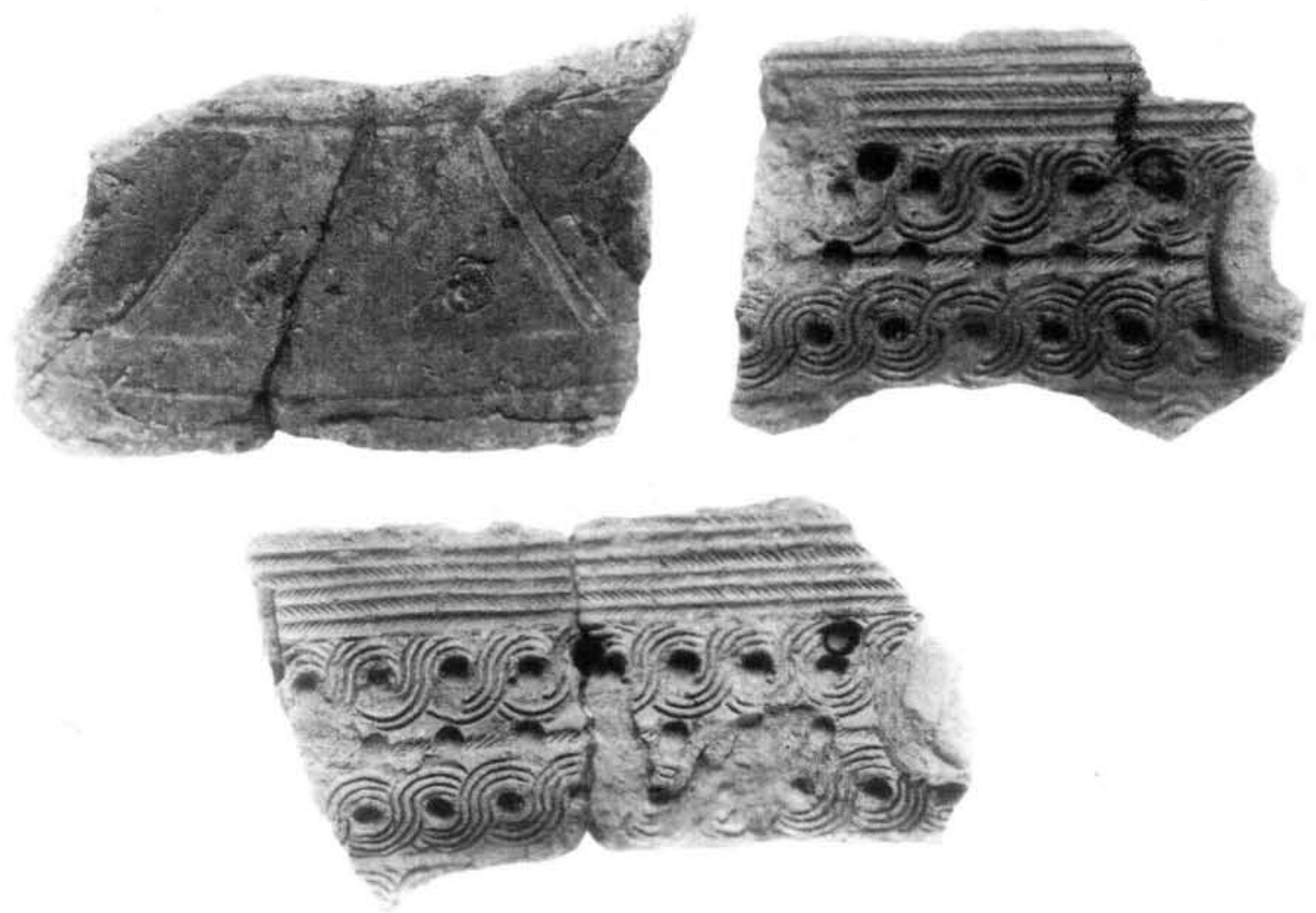

Lám. I. El Castrelin de San Juan de Paluezas. Fragmentos de moldes de sítula.

El que las sítulas a que nos referimos esten representadas en El Castrelín y en otros cuantos castros gallegos por los moldes utilizados para su fabricación, abre, evidentemente, nuevas perspectivas. El contraste entre la metalurgia humilde, con empleo de piezas de cobre, donde no se cuidan las aleaciones, y con hornos rudimentarios que en definitiva está indicando un bajo nivel tecnológico, y la manufactura de esos objetos en cierto modo sofisticados y de minuciosos motivos decorativos, es patente. Su fabricación implica el necesario conocimiento técnico para colar finas placas de metal profusamente decoradas y unirlas con remaches dando forma a la vasija, lo que vuelve a poner de manifiesto los contrastes de la figura del metalúrgico en estas sociedades castreñas.

Dos tipos de producciones tan diferentes parecen adaptarse bien al esquema numerosas veces planteado para la metalurgia de esta época que propone la existencia de dos tipos de metalúrgicos (por ejemplo, Wells, 1990: 60-62 que incluye bibliografía sobre el tema): uno local que producía herramientas y objetos comunes en cada poblado y otro itinerante que hacía circular lingotes, objetos de lujo realizados en centros de producción especiales, innovaciones técnicas y, sería nuestro caso, moldes. División algo artificial que, además, en El Castrelín choca con el inconveniente de que tales moldes son, asimismo, de fabricación local. En efecto, en un estudio de 34 muestras de estos moldes, cerámicas y arcillas del yacimiento, realizado por la Dra. Virginia Galván, en el que utilizó análisis de Fluorescencia de Rayos X para obtener las composiciones geoquímicas y análisis discriminante relativo a óxidos mayoritarios y minoritarios en el tratamiento de esos datos, permite observar la correspondencia geoquímica entre las cerámicas más cotidianas de segura fabricación local y los moldes de sítulas.

Tampoco es necesario recurrir a un artesano más especializado para fabricar objetos sofisticados. Como ya se indicó anteriormente el que los rasgos generales de la metalurgia sean rudimentarios no quiere decir desconocimiento 
de la misma, puesto que la producción de hierro dota de ese nivel al metalúrgico. La mayor o menor habilidad o calidad de una producción creemos está en relación con el interés del artesano para atender la demanda de sus clientes. $\mathrm{Al}$ igual que puede fabricar simples anillos de cobre, también hace fíbulas de fundición en molde, como la encontrada en El Castrelín, claramente de producción local ya que se trata de un metal no depurado con altas tasas de arsénico y antimonio, probablemente obtenido de un mineral también del entorno por las características de las impurezas presentes en el metal. Por tanto, si era capaz de fabricar una fíbula, también tenía capacidad para fabricar sítulas, de las que por desgracia no tenemos ningún fragmento en el yacimiento que pudiera ser analizado para afirmar su relación con el resto de las producciones locales. La única información suministrada por los fragmentos de molde es el análisis cualitativo realizado, que indica la presencia de cobre y plomo, lo que señala la utilización de una aleación plomada.

Si la metalurgia es autóctona parece lógico que también lo sean las materias primas. Una posibilidad de obtención de cobre la tenían los pobladores de estos castros en los filones de cuarzo aurífero de la Serie de los Cabos, donde hay abundantes sulfuros con contenido en cobre (calcopirita) y donde hemos documentado la existencia de enriquecimientos secundarios, tipo carbonatos y óxidos, en sus afloramientos. Darían un rendimiento suficiente para la escala artesanal y las necesidades limitadas y sin alcance comercial de cada taller metalúrgico. En el caso de El Castrelín contamos con un indicio interesante en el núcleo muy próximo de $\mathrm{La}$ Campañana, con plata, plomo, zinc y cobre en dominio carbonatado y lo suficientemente interesante para haber dado lugar en la actualidad a varias concesiones mineras. En algunos tramos de esta mineralización la asociación $\mathrm{Pb}-\mathrm{Zn}$ da paso a otra $\mathrm{Pb}-\mathrm{Cu}$, que debió ser aprovechada en la antigüedad según demuestran los analisis de materiales analizados, donde aparecen cantidades elevadas de plomo como elemento residual de la transformación del mineral al ser mucho más volátil que el cobre. El mineral utilizado debió ser un compuesto polimetálico, que junto al cobre y plomo llevara determinadas cantidades de antimonio y también de arsénico, que no deben extrañar dada la riqueza de la zona en antimonio, al que habitualmente se asocia el arsénico. La abundancia de impurezas de estos elementos ( $\mathrm{Pb}, \mathrm{Sb}$ y As), tanto en los objetos como en los restos de actividad metalúrgica debidas a la falta de refinado del metal en bruto y a unas condiciones rudimentarias de transformación en vasijas-horno, permite suponer el tipo de mineral empleado a pesar de no contar con ningún fragmento de mineral entre los restos estudiados.

El estaño, como el oro - que por el momento no ha aparecido en los dos yacimientos castreños que estudiamos pero que seguramente existió-, era fácilmente obtenible en el lavado de las arenas de los placeres. La posibilidad de su obtención estaba, pues, en los ríos que proceden de los yacimientos de casiterita de la zona de Rubiana (Orense), inmediatamente al oeste de Las Médulas, o incluso de los yacimientos estanníferos más complejos de las inmediaciones de Ponferrada, con menor probabilidad. La plata, en cambio, está presente en los dos castros objeto de este trabajo. En El Castrelín se reduce a unas gotas adheridas al interior de unas cerámicas. La composición de esta plata (PA3365-67) con cantidades elevadas de plomo y algo de cobre, nos indican que se trata todavía de una plata en proceso de refinado, es decir, que se estaba realizando un proceso del que por el momento desconocemos su funcionamiento, similar a una copelación, pero diferente a lo tradicionalmente empleado ya que usa un tipo de recipiente cerámico distinto. Otros análisis presentan cantidades de hierro y estaño que complican aún más la comprensión de este sistema de obtención de plata, que tiene una vez más un carácter local de aprovechamiento de las galenas asociadas al cobre cercanas al yacimiento. En La Corona, por el contrario, se trata de una pieza, una espiral de chapa de ese metal sobre alma de bronce con remates de glóbulos apiñados, aunque es probable que su presencia allí sea resultado de comercio. Su tipología se acomoda bien a la joyería en plata celtibérica tardía, presente en varios tesoros zamoranos (Delibes y Martín Valls, 1982), y a piezas similares, en oro, de Lugo y Orense (Sánchez-Palencia y Fernández-Posse, 1985: 318319 y fig. 8). Los sulfuros de plata/plomo son frecuentes en la zona, conociéndose explotacio- 
nes antiguas de plomo argentífero como La Esperanza, citada por Madoz en Corporales, o en Ponferrada, beneficiadas por «una sociedad Verciana», en la vertiente septentrional de los Montes Aquilianos (Madoz, 1945-50, s.v. Corporales y Ponferrada). En la actualidad estudios de geología local ponen de manifiesto la presencia de suficientes yacimientos de galena para cubrir la escasa demanda de estas comunidades.

En definitiva existe en la zona un notable equilibrio entre el acceso a los recursos potenciales minerales, la tecnología utilizada y la escala de la producción de los metales examinados.

Por el contrario, el hierro parece producto de una minería extractiva tanto más intensa cuanto mayor fuera la demanda de útiles de este material en cada uno de los poblados. Los principales indicios de mineralización de hierro en la zona tienen un claro control estructural. Su alineación se sigue muy bien desde la cuenca del Eria - donde se trata de areniscas ferruginosas y oolitos de hierro-y el Teleno, a cuyo pie se sitúa Corporales, hasta alcanzar la cuenca del Cabrera, donde numerosas poblaciones mantuvieron herrerías hasta el siglo pasado y son frecuentes las pequeñas explotaciones como la de Valdecorrales en Llamas. Las brechas ferruginosas son también fáciles de seguir en la subfosa de Las Médulas, donde se asienta El Castrelín. Contienen limonitas, hematites y oligisto. Madoz (1845-50, s.v. Chana de Borrenes (La) y Ponferrada) se refiere a una "mina de hierro llamada Venera» en la localidad de Chana que surtía a las herrerías de Monte de Valdueza y Pombriego. Esa misma brecha ferruginosa se detecta con especial claridad entre Pardellán (en Orense, al otro lado del Sil) y Castroquilame (sobre el Cabrera). Es decir, el acceso a estas mineralizaciones de hierro para los dos castros objeto de nuestro estudio no era en absoluto dificultoso manteniéndose siempre en distancias menores a los $5 \mathrm{Km}$.

El número de piezas de hierro recuperadas en los dos castros superan en mucho a las de bronce, aunque - exceptuando algunas herramientas - también son en su mayoría objetos de pequeño tamaño. Pero donde se marca claramente la diferencia entre las dos producciones es en la cantidad de escoria: En La Corona supera los $100 \mathrm{Kg}$. y en El Castrelín, además de los más de 40 recogidos en todo el sector excavado de la figura 4, hay que contar con otros $60 \mathrm{Kg}$. de un pequeño sondeo realizado en un segundo recinto que posee este castro.

La producción siderúrgica se muestra, por su lado, algo diferente en ambos castros. No tanto en la cantidad de objetos - que sus muy distintos tipos de deposición desvirtúan- sino en el modo de producción: en La Corona de Corporales parece evidente que en la unidad de ocupación metalúrgica se realizaban las dos industrias, bronce y hierro, de una forma espacialmente muy concreta y en unas instalaciones de gran entidad. Pero tal taller metalúrgico y sus espacios de vertido ocupaban una zona dentro de la trama urbana del núcleo edificado. En El Castrelín el hecho de que el vertedero G recoja en su casi totalidad productos de la manufactura de bronce y que grandes masas de escoria de hierro aparezcan en un segundo recinto secundario abre la posibilidad de que ambas producciones estuvieran en algún momento espacialmente diferenciadas. El motivo de tal diferenciación está en la evidente incomodidad que para el núcleo densamente construido del recinto principal suponía la presencia de una fundición de hierro, con el peligro de fuego, gases y olores que naturalmente genera. Este traslado fuera del caserío permite plantear, a su vez, un volumen de producción más alto en este último castro.

Tal hipótesis parece quedar justificada en otras observaciones referentes a las propias instalaciones de la fundición y forja así como a la dispersión de los vertidos y escorias. En La Corona en el interior del pequeño cobertizo 13 y en un patio cubierto adyacente a él, unos «hoyos» de fundición de no más de medio metro de diametro y otro tanto de profundidad parecen haber sido todo el dispositivo disponible para generar la escoria vertida en los espacios inmediatos; concentrada en ellos, es toda la que, al parecer, se produjo mientras el poblado funcionó como tal (Fig. 2). En El Castrelín la escoria aparece mucho más dispersa. Incluso se utiliza en la solera de algunos espacios comunes o de tránsito mezclada a guijarro para facilitar su drenaje, al igual que aparece formando parte de una especie de "rudus" de que en ocasiones están provistos los pavimentos de las construcciones. Pero, sobre todo, la diferencia del modo 
de producción de hierro entre ambos castros está en el tipo de instalación: en el citado sondeo del recinto secundario de El Castrelín aparecen estructuras cubiertas por un potente estrato de arcilla rojiza. Quizas correspondan a instalaciones metalúrgicas sobre las que, una vez inutilizadas, se vertieron los $60 \mathrm{Kg}$. de escoria más arriba citados. Evidentemente lo reducido de la excavación en esa área marginal del castro no permite todavía ajustar su significación, pero sí mantener las diferencias de nivel en la producción del hierro propuestas.

Nos ilustran sobre el proceso de esa metalurgia, además de la escoria y las manufacturas, varios productos registrados en ambos castros: la torta de hierro de La Corona y una gran masa esponjosa de $11,5 \mathrm{Kg}$. que fue utilizada para, junto a otras piedras, rellenar o clausurar un espacio en una de las reformas constructivas de las varias que se detectan durante la vida del Castrelín.

Puede concluirse que la producción metalúrgica de estas comunidades prerromanas debió cubrir básicamente sus necesidades, quedando evidenciado como toda ella, con excepciones realmente ocasionales, era local. El metal así fabricado se intercambiaría presumiblemente dentro de la propia comunidad que es el castro por productos agrícolas y de equipo, dentro de un sistema de circulación simple y cerrado que no debió casi nunca sobrepasar el propio recinto. $\mathrm{Y}$ en este sentido podemos decir que se trata de una producción evidentemente autárquica. Esas peculiaridades se compaginan perfectamente con la independencia, de un lado y la economía de autosuficiencia, de otro, del modelo de asentamiento que presentan los castros prerromanos de la zona y que no hace más que ratificar el aislamiento que manifiesta cada uno de ellos en su patrón de ocupación del territorio (FernándezPosse y Sánchez-Palencia, 1988: 222-224).

\section{EL IMPACTO ROMANO: AVANCE TECNOLOGICO Y ESPECIALIZACION DE LOS ASENTAMIENTOS}

Ya dijimos al inicio de este trabajo que el proyecto en que se inscribe estudia el cambio provocado en estas poblaciones, cuya metalurgia acabamos de examinar, por la presencia romana. Por lo tanto parece útil hacer, siquiera como mecanismo de contraste, alguna alusión final a la metalurgia de la zona una vez se ha efectuado la integración de las comunidades prerromanas en el sistema romano. Esa presencia romana produce una ruptura en el desarrollo indígena, reorganizándose la zona y sus habitantes en función de una nueva actividad económica: la minería romana del oro que, además de su propio desenvolvimiento planificado y dirigido en un amplio territorio, produce una intensificación en la explotación del resto de sus diferentes recursos. Ese cambio económico genera una fuerte transformación en las estructuras sociales y organizativas de las poblaciones prerromanas que pierden paulatinamente aquella característica de agruparse en organizaciones territoriales independientes y se integran progresivamente en patrones organizativos más amplios y complejos, viéndose obligadas a participar en tareas económicas de índole común. No entraremos aquí en los factores del cambio y en sus indicadores arqueológicos, lo que evidentemente necesitaría un espacio desproporcionado a la finalidad de este trabajo, pero dos o tres pormenores son imprescindibles para comprender el cambio que la presencia romana provoca en la producción del bronce y del hierro.

En primer término, el cambio de modelo de ocupación del territorio entre época prerromana y romana: aunque continúe vigente el tipo de asentamiento castreño, se pasa de un sistema de núcleos independientes, con una ocupación del territorio selectiva y de clara orientación agropecuaria, a otro de asentamientos integrados, funcionalmente diferenciados y complementarios que permiten una explotación intensiva y extensiva de los recursos de la zona (Fig. 5). En segundo término tiene lugar la aparición de unos nuevos asentamientos no castreños. Su razón de ser está en que un tipo de actividad como esa minería del oro a gran escala es impensable sin una infraestructura de abastecimiento específico. Es decir, además de la organización y mantenimiento de las explotaciones y de la mano de obra en ellas ocupada, fue necesario arbitrar el suministro de un notable volumen de materias primas imprescindibles para las labores técnicas (hierro para las herramientas, madera, etc.) y su transformación. 


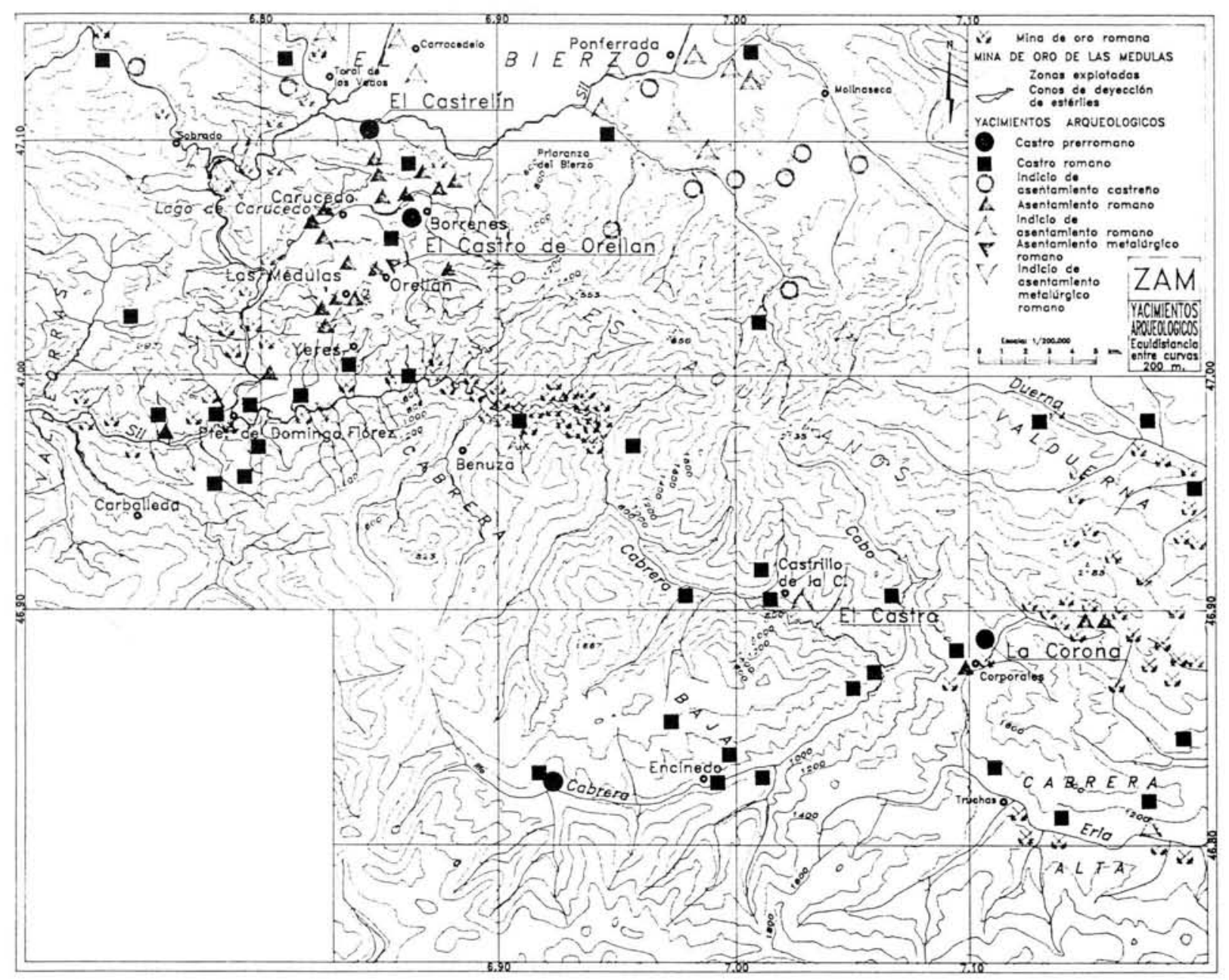

Fig. 5. Zona Arqueológica de Las Médulas. Yacimientos arqueológicos.

Finalmente también es interesante señalar que en la estructura interna de esos asentamientos - sean castros o no- van a terminar desapareciendo las unidades de ocupación, como expresión espacial que eran de una determinada organización social. Y la interdependencia funcional o complementaridad que entre ellas existía dentro del poblado terminará por manifestarse, en época romana, en el territorio, ésto es, entre unos asentamientos y otros. En definitiva, la escala del sistema pasa a ser regional.

En ese nuevo sistema implantado por la administración romana también contamos, como para la etapa prerromana, con dos yacimientos excavados en donde se realizaban labores metalúrgicas que vienen precisamente a ilustrar los tipos de asentamientos definidos sucintamente en los párrafos anteriores. Uno de ellos es un castro -El Castro de Corporalessituado a poco más de $1 \mathrm{Km}$. de La Corona prerromana. El segundo se trata precisamente de uno de esos nuevos asentamientos de infraestructura: el llamado, aunque no lo es, Castro de Orellán, situado en Borrenes y distante de El Castrelín unos $6 \mathrm{Km}$.

El Castro de Corporales, con dos fases que abarcan todo el primer siglo después del cambio de Era y los primeros años del segundo, expresa en su registro arqueológico una clara continuidad con La Corona: las técnicas constructivas, la mayor parte de sus ajuares domésticos, su dieta alimenticia, no han sufrido apenas modifi- 
caciones; pero la ordenación del espacio varía sensible y progresivamente. Y un claro ejemplo de ello es precisamente la instalación metalúrgica. Ya no se trata de que esa actividad sea asumida por una de las muchas unidades de ocupación, sino que se sitúa y pertenece a los espacios comunes o de servicios. De forma que queda superado el modo de producción doméstica. Y así, en un castro cuyo caserío se dispone en terrazas con una distribución regularizada de acuerdo con unos ejes ortogonales, el taller metalúrgico se dispone en su terraza más alta y exigua, fuera, por tanto, del núcleo de habitación.

Orellán, un establecimiento situado en la ladera de un alto cerro denominado El Castro, es un claro ejemplo de tipo de asentamiento de infraestructura con funcionalidad diferenciada. Ya no es una determinada zona del yacimiento la específica como lugar de actividad metalúrgica, es el propio asentamiento. Es más, es muy probable que su situación esté muy directamente determinada por dos factores: de un lado, por la especial función que realizaba con respecto a la gran mina de oro de Las Médulas, ya que en todo el cerro, y sobre todo en una de sus laderas donde se localiza un extenso escorial, existe una fuerte concentración de desechos metalúrgicos. De otro, a su pie existe una brecha ferrosa, la citada más arriba y conocida en la actualidad como el Veneiro, que aflora y ha sido explotada en diversas épocas. Parece claro que las principales actividades que en Orellán se desarrollaban iban desde el beneficio de ese mineral de hierro a la fabricación, basicamente, del instrumental utilizado en la minería del oro.

Nuestros trabajos en este último yacimiento no han pasado de unos sondeos preliminares, pero podemos decir que se trata de un asentamiento que estaba en funcionamiento hacia la mitad del siglo I d. C., momento en que - como en El Castro de Corporales- el utillaje doméstico de sus habitantes no se diferencia todavía apenas del de El Castrelín, con altos porcentajes de cerámica indígena castreña en relación a la romana, pero con una estructura interna $y$, sobre todo, con una función en el conjunto de la ocupación y explotación del territorio diametralmente opuesta a la prerromana. Entre esos cambios no es el menor la organización de la minería no aurífera o la estrategia de los modos de producción de los metales de ella derivados, pero lo que ahora nos interesa, es si se ha producido entre las dos metalurgias -y sobre todo en la del bronce- un cambio tecnológico. Aunque el número de materiales de cobre/bronce no es todavía numeroso, las 13 piezas analizadas procedentes de Orellán permiten disponer de un conjunto de composiciones para comparar con los materiales de los castros prerromanos. $\mathrm{Al}$ margen de la aparición de latones en el poblado romano, se aprecia un rasgo de interés sobre el modo de trabajar el metal en la zona como es la reducción de impurezas de arsénico. En efecto, la tecnología que se practica en época romana introduce un cambio sobre el período anterior en el modo de producir el cobre como metal de base de las aleaciones, que consigue eliminar la presencia de arsénico como consecuencia de una utilización de hornos de reducción y temperaturas de trabajo más elevadas y constantes que las que se podían obtener con el empleo de los recipientes cerámicos ya comentados. Una situación similar se produce entre la metalurgia prerromana y romana de Camerton (Cowell, 1990: 77-78) donde los materiales de la Edad del Hierro tienden a tener mayor concentración de arsénico, níquel y cobalto que los romanos, en los que el arsénico llega casi a desaparecer. La explicación a estas diferencias la atribuye Cowell a un cambio en el origen del mineral, que se considera importado en época romana. Sin embargo, no creemos que ésta pueda ser la explicación correcta en el caso de la región leonesa (Fig. 6), sino que habría que atribuirlo más bien a un avance técnico. El arcaismo tecnológico detectado en la fase anterior a la romanización produce un metal con elevadas impurezas de arsénico y antimonio, que son fácilmente eliminables con el empleo de los hornos romanos que logran temperaturas más elevadas y que sin duda se utilizan cuando se trata de producciones más comercializadas, frente a la producción doméstica autosuficiente.

Si la explicación dada para la eliminación de una mayor cantidad de impurezas de arsénico en el metal es correcta, debería esperarse que esto mismo sucediera con las impurezas de antimonio, cuyo comportamiento y volatilidad con altas temperaturas es similar al del arsénico. En los análisis de los materiales de Orellán desaparece, como ya se ha comentado, el arsé- 


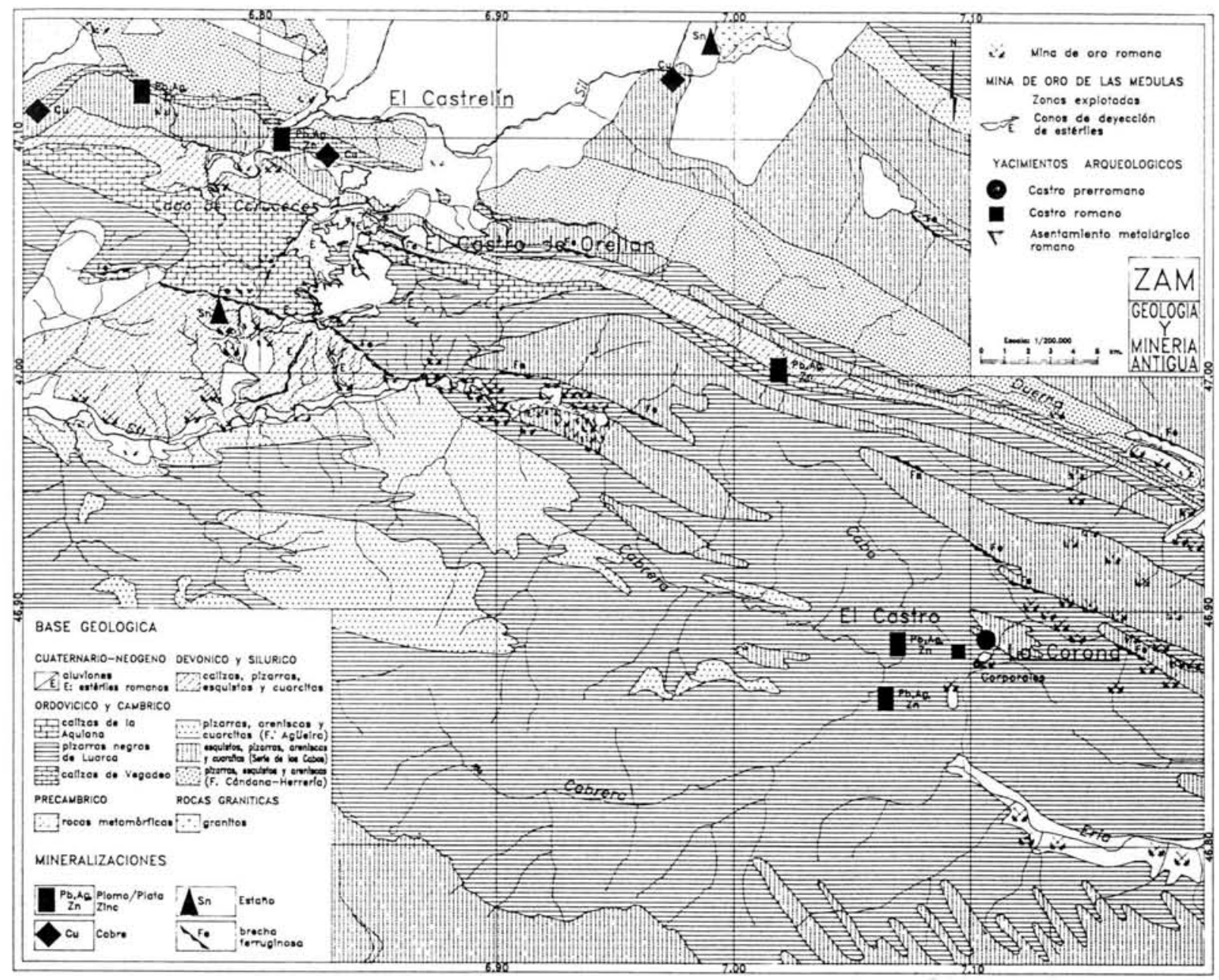

Fig. 6. Zona Arqueológica de Las Médulas. Minería antigua.

nico, pero el antimonio mantiene aún en bastantes casos proporciones relativamente elevadas, superiores al $0,25 \%$, aunque no se alcanzan valores tan elevados como en los materiales del Castrelín. Esta menor presencia de antimonio, pero manteniendo proporciones elevadas, no queda todavía satisfactoriamente explicada si procediese del mineral de cobre. Ahora bien, estas piezas suelen estar realizadas con una aleación de bronce, donde además del cobre participa el estaño en proporción variable. El antimonio puede asociarse también a este elemento en el mineral e introducirse por lo tanto en la composición del metal. La mineralogía del Sn es compleja y, aunque la casiterita es el óxido y mineral más frecuente, a bajas temperaturas se forman sulfuros entre los que se encuentran sistemás complejos como el que forma el estaño con Sb y Pb (Martín-Izard, 1991: 228). En consecuencia, cabría pensar que el antimonio que se detecta en estos materiales procede del estaño aleado y por tanto ha de pensarse en un aprovechamiento de minerales sulfurados que debieron ser explotados mediante trabajo de minería, en contraposición con la posibilidad de la explotación de la casiterita mediante la técnica de bateo en época prerromana.

En definitiva, vemos como una de las actividades económicas más concretas que se realizan en la zona, como es la producción 
metalúrgica del bronce y del hierro, cambia de forma notablemente radical a raíz de la presencia romana en la Zona Arqueológica de Las Médulas. Esa metalurgia prerromana, descuidada y de bajo nivel tecnológico, que produce manufacturas de gran variabilidad en sus componentes y en procesos poco controlados, desaparece para dar lugar a productos más depurados. Pero donde realmente se produce una auténtica transformación es en los aspectos que se refieren al modo y a la escala de esa producción: mientras que en los castros prerromanos se trata siempre de producciones escasas y artesanas que cubren exclusivamente la demanda interna, los asentamientos romanos experimentarán una fuerte intensificación de la producción metalúrgica -con un volumen de escoriales lejos ya de esa producción artesanal-y con un marcado cambio de escala. Mientras la metalurgia prerromana jamás supera ese núcleo de producción autárquica que es el castro, en época romana aparecen asentamientos que son indudablemente centros de esa manufactura, es decir, cuya actividad preferencial - quizás podría decirse que exclusiva- es la producción de metal. Esos asentamientos marcadamente diferenciados en su funcionalidad cubren así las necesidades de instrumental metálico de todos aquellos otros que se organizan en torno a las explotaciones de oro, al mantenimiento de su infraestructura y su mano de obra, en un sistema de ocupación y explotación del territorio evidentemente planificado y de fuerte rentabilidad económica.

\section{BIBLIOGRAFIA}

CARballo Arceo, L. X. (1983): “Aportación al estudio de las sítulas en el Occidente de la Península Ibérica", Cuadernos de Estudios Gallegos, XXXIV, 99: 7-32.

- (1987): Castro da Forca. Campaña 1984. Arqueoloxía/Memorias, 8. Xunta de Galicia. Santiago de Compostela.
Cowell, M. R. (1990): "Scientific Report». En R. Jackson: Camerton. The Late Iron Age and Early Roman Metalwork. British Museum Publications. Londres: 69-80.

Clarke, D. L. (1979): “The Economic Context of Trade and Industry in Barbarian Europe till Roman times". En D. L. Clarke (ed.): Analytical Archaeologist: Collected Papper 263-331. Academic Press. Londres.

FERnÁNDEZ-Posse, M. D. y SÁNCHEZ-PALENCIA, F. J. (1988): La Corona y El Castro de Corporales II. Campaña de 1983 y prospecciones en La Cabrera y La Valderia (León). Excavaciones Arqueológicas en España, 153. Ministerio de Cultura. Madrid.

IGME (1975): Mapa Metalogenético de España E. 1:200.000. H. 18, Ponferrada. Inst ${ }^{\circ}$ Tecnológico GeoMinero de España. Madrid.

MADOZ, P. (1845-1850): Diccionario Geográfico-EstadísticoHistórico de España y sus posesiones de Ultramar. Castilla y León. (Reedición de la Prov. de León. Valladolid. 1983).

Nosek, E. M. (1985): "The polish smelting experiments in furnaces with slag pits". En P. T. Craddock y M. Hughes (eds.): Furnaces and smelting techology in Antiquity. British Museum Occasional Paper, 48: 165-177.

MARTíN-IZARD, (1991): "Yacimientos de estaño-wolframio». En R, Lunar y R. Oyarzun: Yacimientos minerales. Ed. Centro de Estudios Ramón Areces: 227-263.

RENFREW, C. (1986): «Introduction: Peer polity interaction and socio-political change». En C. Renfrew y J. F. Cherry (eds): Peer Polity Interactión and socio-political Change. Cambridge University Press: 1-18.

RowLAND, M. J. (1972): «The Archaelogical Interpretation of Prehistoric Metalworking». World Archaelogy, 3: 210223.

Sánchez-Palencla, F. J. y Fernández-Posse, M. D. (1985): La Corona y El Castro de Corporales 1. Truchas (León). Campañas de 1978 a 1981. Excavaciones Arqueológicas en España, 141. Madrid.

SánCHez-Palencia, F. J. y Fernández-Posse, M. D. (1986): "Habitat y urbanismo en La Corona de Corporales". Arqueología Espacial, 9. Teruel: 139-154.

SÁnchez-Palencia, F. J.; Fernández-Posse, M. D.; Fernández Manzano, J.; Alvarez, Y. y López, L. (1990): «La Zona Arqueológica de Las Médulas». AespA, 63: 249-264.

ToRnos, F. y GUMIEL, P. (1992): «El wolframio y el estaño: aspectos económicos y metalogenéticos". En Recursos minerales de España. CSIC. Madrid: 379-394.

Wells, P. S. (1988): Granjas, Aldeas y Ciudades. Comercio $y$ origenes del urbanismo en la Protohistoria europea. Ed. Labor. Madrid. 